DE-FC07-98ID13693

\title{
DIE MATERIALS FOR CRITICAL APPLICATIONS AND INCREASED PRODUCTION RATES
}

David Schwam

John F. Wallace

Sebastian Birceanu

Case Western Reserve University

November 2002

Work Performed Under Contract DE-FC07-98ID13693

For

U.S. Department of Energy

Assistant Secretary for

Energy Efficiency and Renewable Energy

Washington D.C. 


\section{CONTENT}

Acknowledgments........................................................3

Abstract.......................................................................4

1. Critical Applications in Die Casting....................................7

2. Die Failure Mechanisms...............................................8

2.1 Thermal Fatigue Failure in Die Casting Dies.........................9

2.2 Thermal Fatigue Resistance Evaluation Criteria......................13

2.2.1 Thermal Conductivity............................................14

2.2.2 Thermal Expansion Coefficient.................................15

2.2.3 Elastic Modulus and Strength.................................16

2.2.4 The Effect of Thermal Cycling on the Microstructure.........17

2.3 Soldering and Washout Damage....................................17

3. Non-traditional Die Materials............................................19

3.1 Nickel-base Alloys and Superalloys..................................19

3.2 Titanium Alloys....................................................22

3.3 Copper-based Alloys...............................................23

3.4 Refractory Metals and Alloys.......................................25

4. Results and Discussion......................................................27

5. Summary and Conclusions..........................................32

6. References..................................................................34

$\begin{array}{ll}\text { FIGURES } & 37\end{array}$ 


\section{ACKNOWLEDGEMENTS}

This research investigation was supported by the Department of Energy, Office of Industrial Technology through the Cast Metal Coalition program. Guidance for this work was provided by the Die Materials Committee of the North American Die Casting Association. The efforts of Mr. Stephen Udvardy of NADCA and the DMC are gratefully acknowledged.

A wide range of materials and coatings were provided as in-kind contributions to this project by manufacturers and suppliers. Bohler Uddeholm and Kind provided steels, Brush Wellman provided copper-based alloys, CMW and Kulite provided tungsten-based alloys, CSM (an H.C. Stark company) provided molybdenum-based alloys, Allvac provided nickel-based alloys and Dynamet provided titanium based alloys. Coatings were provided by Badger Metals, Dynamic Metal Treating, IonBond, Balszers and Phygen. In addition, in-plant evaluation of some of these materials under production conditions was undertaken by Metaldyne (previously Lester Die Casting) and Saint Clair Die Casting. Valuable technical support and advise were received from DCD Technology on tooling issues.

This publication was prepared with the support of the U.S. Department of Energy (DOE), Award. DE-FC07-98ID13613. However, any opinions, findings, conclusions or recommendations expressed herein are those of the authors and do not necessarily reflect the views of the DOE. 


\section{ABSTRACT}

Die materials for aluminum die-casting need to be resistant to heat checking, and have good resistance to washout and to soldering in a fast flow of molten aluminum. To resist heat checking, die materials should have a low coefficient of thermal expansion, high thermal conductivity, high hot yield strength, good temper softening resistance, high creep strength, and adequate ductility. To resist the washout and soldering, die materials should have high hot hardness, good temper resistance, low solubility in molten aluminum and good oxidation resistance. It is difficult for one material to satisfy with all above requirements. In practice, $\mathrm{H} 13$ steel is the most popular material for aluminum die casting dies. While it is not an ideal choice, it is substantially less expensive to use than alternative materials. However, in very demanding applications, it is sometimes necessary to use alternative materials to ensure a reasonable die life. Copper-base, nickel-base alloys and superalloys, titanium-, molybdenum-, tungsten-base alloys, and to some extent yttrium and niobium alloys, have all been considered as potential materials for demanding die casting applications. Most of these alloys exhibit superior thermal fatigue resistance, but suffer from other shortcomings.

The current project conducted a systematic evaluation of potential die materials and diffusion coatings available commercially. The first group of materials evaluated were advanced die steels developed in the late 90's and marketed since 2000. Two representatives of this group are the BohlerUddeholm Dievar and the Kind Co. TQ1. In 
general, these steels are characterized by lower silicon and vanadium and higher molybdebum content relative to H13. In addition, they have very low trace element content and are being processed by the latest steel making technologies. They have high Charpy V-notch impact strength, often in excess of $20 \mathrm{ft}-1 \mathrm{~b}$. This high toughness allows use of components at higher hardness than the traditional 44-46HRC, without concern of gross-cracking. The temper resistance of these steels is markedly superior to H13. This fact contributes to the superior thermal fatigue demonstrated by Dievar and TQ1. An interesting finding of this study was the difference in the thermal fatigue cracking pattern between these steels and H13. While in H13 the cracks were fewer but cut deeper into the corners of the thermal fatigue specimen, the new steels exhibit more but very shallow surface cracks. Presumably, these cracks that do not propagate deep could be readily tolerated. There is however anecdotal evidence of severe washout damage in gating areas that was not encountered previously in H13. A possible explanation would be that the fine surface cracks interfere with the flow of the molten metal resulting in excessive washout. This hypothesis has yet to be confirmed experimentally.

Copper-based alloys demonstrated excellent thermal fatigue behavior. The high thermal conductivity results in rapid heat transfer from the surface to the water in the cooling line. The thermal fatigue specimen stays relatively cold when tested under identical conditions with steel. Unfortunately, unprotected copper alloys tend to dissolve in molten aluminum if heated above a certain temperature threshold. Impingement of a stream of molten aluminum onto an unprotected copper based insert, slide or core will inevitably result in washout or severe soldering. The nickel-based alloys evaluated in the 
study suffered from the same problem, i.e. severe soldering and washout. Rather than being soluble, nickel-based alloys form intermetallics with molten aluminum. When unprotected and overheated they will underperform at best.

Molybdenum and tungsten alloys are excellent performers under severe thermal fatigue and soldering conditions and should be used for demanding applications. Admittedly these alloys are expensive, hard to machine, brittle and only available in relatively small sizes. Neverthenless, in certain demanding situation they may be the only viable choice to ensure reasonable die life.

Nitro-carburized coatings did not improve the thermal fatigue resistance; some even decreased it. It should be remembered however, that the main purpose of these coatings is to improve the soldering resistance. Sacrificing some thermal fatigue resistance to gain better soldering resistance may be a desirable compromise in some applications. 


\section{Critical Applications in Die Casting}

Die casting is a process of choice in many manufacturing industries - automotive, hardware, electrical and electronics, computers and many others. It produces aluminum, zinc and magnesium alloy components with satisfactory properties at competitive prices. The main advantages of die casting are [1,2]:

- Die casting is able to provide complex shapes within close tolerances;

- High rates of production with little or no machining required;

- Die cast parts are durable, dimensionally stable, and have a good appearance;

- Die castings are monolithic; they combine many functions in one complex shaped part;

During the aluminum die casting process, some parts of the die are subjected to very severe conditions of temperature and stress. Generally, these are thin sections, cores, corners and slides surrounded by molten metal. In many of these cases the heat transfer is two-dimensional. Consequently, these sections of the die must absorb much more heat than the rest of the die. Often these are the sections that fail prematurely either by soldering or heat checking.

A high production rate is always desirable since it has a major impact on profitability. Sometimes this consideration overrides die life concerns. Under these circumstances, it becomes critical to create conditions for rapid heat extraction from the surface, 
dissipation inside the material, or rapid heat transfer to a "heat conveyor" such as a cooling line. High heat diffusivity die materials can contribute to rapid transfer of the heat away from the casting. However, any material selected for these applications must withstand the harsh conditions of the die casting process without failing prematurely.

\section{Die Failure Mechanism}

The durability of materials in molten aluminum is a great concern in die casting, containment of liquid metals and semi-solid processing [3]. The main failure modes identified for aluminum die casting dies are physical erosion (wash-out), chemical attack (corrosion), gross-cracking (cleavage cracking) and thermal fatigue cracking (heat checking) $[1,2,4,5]$. Erosion occurs when there is a fast flow of molten metal relative to the surface of the die; it becomes more severe in the presence of hard particles (such as primary solid silicon in 390 alloys or $\mathrm{SiC}$ particles in metal matrix composites. Chemical corrosion refers to penetration and dissolution of materials by the melt as well as the formation of interphase layers, when relative motion between the solid materials and the melt is negligible [3]. Gross cracking is usually catastrophic and may result in complete cracking of the die. Cracking and fracture of die occurs when the die material is stressed beyond its fracture strength. This can occur even when the mechanical stress applied on the die is below the yield stress. It results from a combination of residual stresses, thermal and mechanical stresses [6]. This type of failure is related to the inherent resistance of the die material to brittle fracture termed "fracture toughness". 


\subsection{Thermal Fatigue Failure in Die Casting Dies}

The life of dies used at elevated temperatures is often determined by their thermal fatigue properties [7]. The fatigue failure produced by fluctuating thermal stresses is known as thermal fatigue. Thermal stresses occur when the expansion or contraction of a part as a result of a temperature change is restrained [8]. The constraint may be internal or external [9]. External constraints produce forces that act on a component that is alternately heated and cooled. Internal constraints may result from temperature gradients across the section (simply because heat is not able to flow quickly enough in response to the external changes), structural anisotropy and different coefficients of expansion in adjacent phases or grains [10]. Thermal fatigue resulting from the action of internal constraints can also be defined as thermal cycling damage.

Temperature gradients form as a result of heating and cooling of the surface during injecting the molten metal, ejection and the lubricant spraying stages of the die casting cycle [4, 11]. When molten aluminum is injected, the die surface heats up, creating a steep temperature gradient between the surface and the cooler underlying mass of the die. As a result, the surface wants to expand more than the interior. Because the interior is more massive, it prevents the surface layer from expanding. As a result of this internal restraint, the surface is placed under compression. As heat is conducted into the underlying layers, the surface temperature decreases rapidly. When the casting is ejected, the surface of the die cools down. The spray of die lubricant further decreases the surface 
temperature [12]. The surface cools faster than the interior, the compression stresses are relieved and tensile stresses may be created.

The temperature gradient and the coefficient of the thermal expansion of the material determine the magnitude of the surface stress. For the simple case of a bar with fixed end supports, the thermal stress generated by a temperature change $\Delta T$ is:

$$
\sigma=\alpha E \Delta T
$$

where $\alpha$ is the linear thermal coefficient of expansion and $\mathrm{E}$ is the elastic modulus [8]. For a biaxial condition, the stress is given by:

$$
\sigma=\alpha E \Delta T /(1-v)
$$

where $v$ is Poisson's ratio. The thermal stresses never fully develop because $\alpha, E, v$ and the thermal conductivity all change with temperature [13].

The fatigue damage inf metallic materials can be subdivided into the stages of crack initiation, subcritical crack propagation, and final unstable fracture [14]. Crack initiation usually occurs at stress concentration sites originating from component geometry, machining irregularities or surface imperfections [15]. During the compressive part of the cycle, the increase in temperature lowers the yield strength of material, and the compressive strain may become plastic when the substrate prevents deformation. During the tension part of the cycle, the concentrated thermal stress is larger than the yield strength of the material, and reversed plastic deformation may occur. After sufficient number of cycles, the localized plastic deformation will cause a fatigue crack. Once a crack has initiated, propagation occurs along a plane perpendicular to the maximum tensile stress. Fatigue cracks in steels can deviate noticeably from the expected plane of 
propagation when large prior austenite grain boundaries are present or when another crack is in close proximity [15]. The influence of other cracks on crack propagation is explained by the interaction of the highly stressed regions at the tips of the cracks. When the crack tips are close enough, this interaction changes the general state of stress. This provides an attraction of cracks to each other until the cracks are joined by reversed crack branching or forking. When the side branches join, they produce the classical crazecracking pattern [16]. Several opinions exist about the driving force for crack propagation. One opinion is that cracks widen and deepen by the wedging action of the molten metal or oxide that is forced into them in each shot [17]. Another is that crack propagation occurs only by the thermal fatigue mechanism. In this event, propagation has to occur during the cooling cycle, since that provides the tensile stress necessary for crack propagation. Once a fatigue crack is formed, it will continue to grow because of the stress concentration effect even when the tensile stress is low [18].

The damage caused by thermal cycling can be separated into stages [14]:

- crack initiation at the surface;

- crack linking at the surface;

- growing of small cracks in depth direction from the crack net;

- growing of the largest crack to the complete failure.

The generation and evolution of thermal stress have been explained based on the type of thermal transients that occur during the service of a die subjected to thermal shock-thermal fatigue [10]. Suppose a heavy section at low temperature is suddenly brought in contact with a hot molten metal. As explained before, the surface tends to expand against the remaining material and goes into compression, yielding along OQ 
(Figure 1). Because of the heat transfer towards the core, the temperature gradient decreases and the system expands, taking the surface into tension at $\mathrm{R}$. The residual tension is responsible for intergranular cracking. When the material is further subjected to rapid cooling this series of events is reversed. The surface now goes into tension, as it tends to contract, with a tension peak at point $\mathrm{S}$ that promotes transgranular cracking since the corresponding strain rate is high and the temperature decreases. Later, when the die cools, the yielded section at A goes into compression. The compression stress at P (at the original strain level) is not particularly damaging, but when many cycles are repeated, the system goes into a hysteresis loop at the surface (PQRS), leading to thermal fatigue cracking due to the reversed deformation.

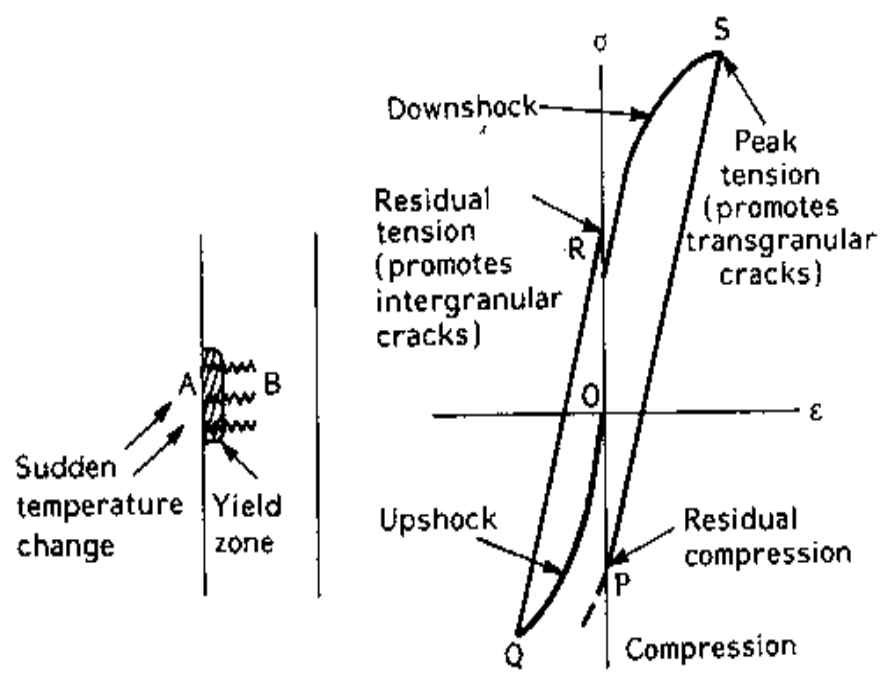

Figure 1. Hysteresis Loop at the Surface of a Material Subjected to Cyclic Heating and Cooling [10]. 


\subsection{Thermal Shock and Thermal Fatigue Resistance Evaluation Factors - Materials Evaluation Criteria}

A common measure of thermal shock resistance is the maximum sudden increase in the surface temperature that a material can sustain without cracking [19]. The thermal shock resistance and thermal fatigue resistance depend on a number of material properties. These include the thermal expansion coefficient $\alpha$, thermal conductivity $k$, thermal diffusivity $K$, elastic modulus $E$, fracture toughness $K_{I c}$, tensile (fracture) strength $\sigma_{f}$ and upon the additional parameters of heat transfer coefficient $h$, specimen size and duration of thermal shock $[4,19,20,21]$.

A commonly used thermal shock - thermal fatigue resistance parameter is the merit index of $R=\sigma_{f} f E \alpha$ or $R^{\prime}=k \sigma_{f} / E \alpha[4,19,21]$. For large values of Biot number $(\beta=b h / k)$, i.e. large heat transfer coefficient $h$, radius or thickness $r$ or $b$, respectively, and small thermal conductivity $k$, or when thermal strains are the result of the material being mechanically constrained, the thermal shock resistance is determined by $R$. For very small Biot numbers, i.e. small heat-transfer coefficients, small radius or thickness, and large conductivity, or when thermal strains are a consequence of thermal gradients resulting from rapid heating or cooling, the thermal shock resistance is determined by $R^{\prime}$. If we consider the thermal fatigue as a series of repeated thermal shocks, these 
parameters can be used to describe the thermal fatigue resistance and for ranking of materials.

In this respect, the effect of elements incorporated into the chemistry of an alloy should be considered based on their contribution to [22]:

a) Thermal properties of the material: coefficient of thermal expansion, specific heat, and thermal conductivity

b) Material strengthening through carbide formation, solid solution strengthening with consequent increase in the capacity for withstanding repeated strains and with improved creep performance.

c) Microstructural stability and oxidation resistance

\subsubsection{Thermal Conductivity}

The thermal conductivity is the quantity of heat transmitted, due to unit temperature gradient, in unit time under steady conditions in the direction of the temperature gradient. This condition occurs when the heat transfer is dependent only on the temperature gradient [23]. Under the conditions described above, higher thermal conductivity will reduce thermal fatigue by establishing a lower thermal gradient between the surface and the underlying layer. Equations (2-1) and (2-2) indicate that a lower temperature gradient will decrease the stress in the material. The successful use of molybdenum inserts in pressure die casting dies results to a large extent from the high 
value of the thermal conductivity. However, because of its variation with temperature, the influence of this parameter may diminish under operating conditions. For instance, ferritic steels have generally higher values of thermal conductivity than austenitic steels, but at high temperature, say at $1073 \mathrm{~K}$, their thermal conductivities become similar [22].

\subsubsection{Thermal Expansion Coefficient}

The coefficient of linear thermal expansion is the ratio of the change in length per degree $\mathrm{K}$ to the length at $273 \mathrm{~K}$. The coefficient of volume expansion is about three times the linear coefficient [23]. The combination of the temperature gradient and the coefficient of thermal expansion determines the magnitude of stress, as shown by equation (2-1). The expansion in the axial direction of an element subjected to a temperature $T_{x}$ will be, according to Duhamel's analogy [20]:

$$
\varepsilon=\alpha T_{x}
$$

and the compressive stress induced by bringing the element back to its initial dimension, will be:

$$
\sigma=-E \alpha T_{x}
$$

Among metals, refractory metals have the lowest thermal expansion coefficients [22]. Consequently, refractory alloys have superior resistance to thermal fatigue. 


\subsubsection{Elastic Modulus and Strength}

The elastic modulus is a measure of the stiffness of the material. It is defined as the ratio of the stress and strain in the elastic deformation range:

$$
E=\sigma / \varepsilon
$$

For a given strain, a lower modulus results in lower stress. Some metallic, but especially structural ceramic materials are susceptible to failure when thermally shocked due to a high Young's modulus, combined with relatively high thermal expansion coefficient, low strength and low thermal conductivity [22].

In general, a material with a low Young's modulus and a high value of yield strength is desirable, as the elastic component of the strain is large and the plastic component is small during a typical thermal cycle. The best combination of properties is a high strength-high ductility (high toughness) material. Unfortunately high strength is often associated with a low value of ductility.

A very important issue related to thermal fatigue resistance of materials is the hot hardness and the variation of strength with temperature. At high temperatures, the surface loses strength and hardness, especially in steels. This fact will lower the thermal fatigue resistance. The parameters $R$ and $R^{\prime}$ will therefore not change their values much with temperature because of variation in $E \alpha$, which is roughly constant with temperature [10]. The change is primarily due to the drop in strength at higher temperature that can not be compensated by the rise in thermal conductivity. 


\subsubsection{The Effect of Thermal Cycling on the Microstructure}

The prolonged exposure to elevated, cyclic temperatures and thermal stresses can cause marked changes in the microstructure [22]. These changes in the metallurgical structure contribute to failure by reducing the strength and are referred to as microstructural instabilities. Sources of instabilities include transgranular-intergranular fracture transition, recrystallization, aging or overaging, phase precipitation decomposition and coarsening of carbides. Borides or nitrides, intermetallic phase precipitation, delayed transformation to equilibrium phase, order-disorder transition, general oxidation, intergranular corrosion, stress-corrosion cracking, slag-enhanced corrosion, and contamination by some trace elements may also cause microstructural instabilities [5].

\subsection{Soldering and Washout damage}

Washout involves removal of die material by the impinging jet of an incoming molten metal stream. Washout in aluminum die-casting dies is accompanied by corrosive wear, erosive wear and soldering. Excessive washout results in the damage of the die surface and finally leads to the failure of the die. Corrosive wear is defined as the dissolution of die material in the molten aluminum and the formation of intermetallic layers. Corrosion is caused by the following facts: 
- Iron and most of the alloying elements in the die steel are more or less soluble in liquid aluminum.

- The high die temperatures may cause oxidation of the die surface.

- Intermetallic layers may form at die surface.

Erosive wear is defined as the gradual removal of material from the die with every liquid aluminum impingement. This takes place as a result of the motion of the aluminum melt, which can reach velocities within the range of 20 to $60 \mathrm{~m} / \mathrm{s}$ in gate area. The main erosion mechanisms are:

- Liquid-impingement erosion that creates pits on the eroded sample surfaces.

- Cavitation, which is the result of the formation and collapse of bubbles (cavities) in a fluid due to local pressure fluctuations.

- Solid erosion, which is caused by the impact of solidified particles (primary Si particles, oxide particles and impurities or intermetallic particles) during filling.

Soldering is defined as the adhesion of the cast metal to the die or core surface. Chemical and mechanical reactions occur during the filling and solidification stage due to the affinity of the aluminum alloy and die substrate. The chemical reactions often result in the formation of intermetallic layers at the die substrate/ aluminum alloy interface. Mechanical interlocking will also result in aluminum buildup on the die surface when the molten aluminum penetrates into cracks in die surface. The consequent buildup of the aluminum alloy that occurs at the interface is called soldering. Soldering will cause sticking problems when the casting is ejected and it can also give rise to adhesive wear when the casting is separated from the die. 
Die materials for aluminum die-casting should be resistant to heat checking, resistance to washout and to soldering in a fast flow of molten aluminum. To resist heat checking, die materials should have a low coefficient of thermal expansion, high thermal conductivity, high hot yield strength, good temper softening resistance, high creep strength, and adequate ductility. To resist the washout and soldering, die materials should have high hot hardness, good temper resistance, low solubility in molten aluminum and good oxidation resistance. It is difficult for one material to satisfy with all above requirements. In practice, $\mathrm{H} 13$ steel is the most popular material for aluminum die casting dies. Copper-base, nickel-base alloys and superalloys, titanium-, molybdenum-, tungstenbase alloys, and in a small measure yttrium and niobium alloys, have been considered as potential materials for die casting dies.

\section{Non-traditional Die Materials}

\subsection{Nickel-base Alloys and Superalloys}

With a superior creep strength and good oxidation resistance, nickel-base alloys are widely used for high temperature applications, especially in gas turbine applications. The superalloys are complex materials capable of maintaining some of their room temperature physical and mechanical properties up to elevated temperatures. Thermal 
fatigue is one of the major concerns in superalloy turbine blades, since a great number of failures occur because of it [24].

Between solid solution and age-hardening nickel alloys, the latter are characteristically more unstable. Structurally, they are in a state of transition to equilibrium. Therefore, the temperature and stress induced atomic migration will cause aging to continue, resulting in reduced strength. The most important phases present in the microstructure are $\gamma$ matrix, $\gamma^{\prime}$ intermetalic precipitatse, $\mathrm{MC}, \mathrm{M}_{23} \mathrm{C}_{6}, \mathrm{M}_{6} \mathrm{C}$ carbides (last two mostly on the grain boundaries), and other constituents like $\sigma, \mu$ or Laves phases [26]. The principal age-hardening phase in this type of alloys is $\gamma^{\prime} \mathrm{Ni}_{3}(\mathrm{Al}, \mathrm{Ti})$ phase. When a high strength nickel alloy is exposed a long time to stress at elevated temperatures, a considerable amount of $\gamma^{\prime}$ coarsening may occur. The dashed line in Figure 2 indicates the beginning of a slight increase in the slope of stress-rupture life curve, which is believed to be caused by $\gamma^{\prime}$ coarsening due to overaging [5].

However, nickel-base precipitation-hardening alloys are generally stable at temperatures under $1200{ }^{\circ} \mathrm{F}$. For alloys like Waspalloy, Astroloy and René 95, a prolonged exposure at temperatures above $650^{\circ} \mathrm{C}\left(1200^{\circ} \mathrm{F}\right)$ leads to a slight coarsening of the strengthening phase. Unless the alloys are operated at temperatures well into or above their aging ranges (1100 to $\left.1500{ }^{\circ} \mathrm{F}\right)$, no significant microstructural effect should be noted. 


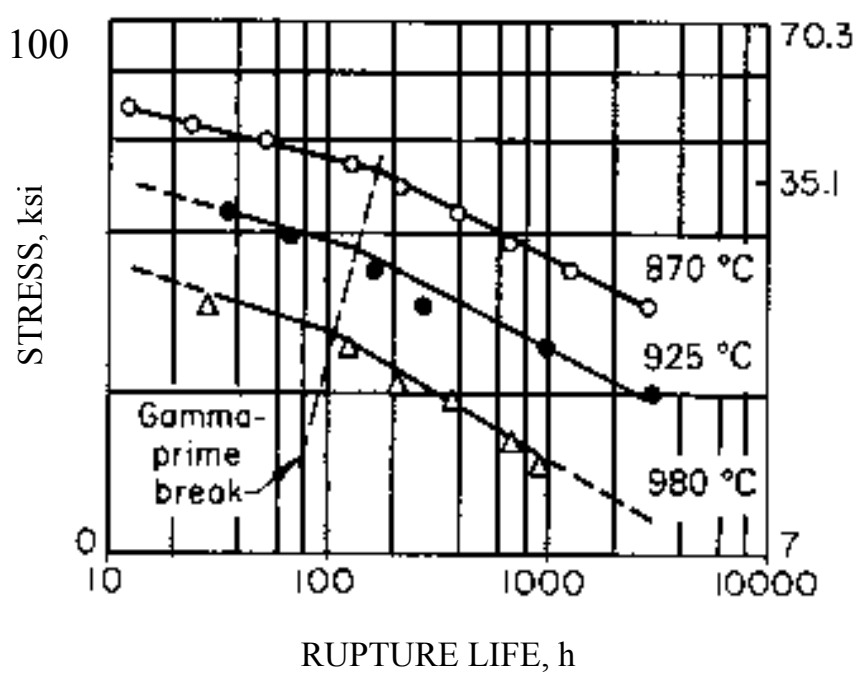

Figure 2. Stress-rupture life for nickel-base alloy B-1900 [18]

Inconel 718, a niobium-hardened alloy, is often used at temperatures above $1150{ }^{\circ} \mathrm{F}$, its final aging temperature. Although some minor coarsening of $\gamma^{\prime}$ has been noted, no detrimental effects occur up to $1200^{\circ} \mathrm{F}$ [30]. In Nimonic 263 the structure consists of $\gamma^{\prime}$ precipitates distributed in the matrix and coarse $\mathrm{M}_{23} \mathrm{C}_{6}$ carbides along the grain boundaries. Besides some dissolution of the $\gamma^{\prime}$ phase and considerable plastic deformation, no other significant effect has been observed after prolonged exposure of this alloy to high temperatures[24].

Previous studies of thermal fatigue in nickel-based superalloys have shown that crack initiation can occur in either intergranular or transgranular mode. Intergranular cracks start at oxidized exposed grain boundaries at higher temperatures due to the 
contribution of creep and environmental attack. Transgranular cracking is predominant at lower temperatures and higher frequencies.

\subsection{Titanium Alloys}

The very attractive strength-to-weigh ratio, as well as the useful strength and oxidation resistance at relative high temperature, placsd titanium and its alloys among the materials with potential in elevated temperature applications. A number of titanium alloys for use in gas turbine engines, hot sections of airframes and other applications have been developed [27]. Compared to steels and nickel-base alloys the resistance of titanium alloys to contact with molten aluminum is much higher [2]. Titanium can exist in two crystallographic forms: the Ti- $\alpha$ phase, a hexagonal close-packed structure stable at room temperature which at $883{ }^{\circ} \mathrm{C}\left(1621^{\circ} \mathrm{F}\right)$ transforms into $\beta$ phase (body-centered cubic structure). Alloying elements can be $\alpha$ or $\beta$ stabilizers producing a range of possible microstructures. Based on the phases present, titanium alloys can be classified as either $\alpha$, near- $\alpha, \alpha-\beta$, near- $\beta$ or $\beta$ alloys. Some characteristics of these alloys are [27,29]:

- $\alpha$ alloys (with $\mathrm{Al}$ and $\mathrm{Sn}$ ) cannot be strengthened by heat treatment, since there is no strengthening phase $(\beta)$. They are annealed or recrystallized, and have good weldability. - near- $\alpha$ alloys (with Al, Sn, Zr, and eventually Mo), with $\alpha$ as the main phase and some retained $\beta$, can be strengthened by heat or thermomechanical treatment. They seem to be the most thermally stable among the Ti alloys (thermal stability is the capacity of maintaining the properties after service at elevated temperature). 
- $\alpha-\beta$ alloys (with both $\alpha$ and $\beta$ stabilizers in a balanced ratio) are the most used ones, due to the very good combination of strength and ductility from solution treating and aging. $-\beta$ and near- $\beta$ alloys are richer in $\beta$ stabilizers and leaner in $\alpha$ stabilizers than the rest of the titanium alloys. They have high hardenability, and in solution treated conditions (100 $\%$ retained $\beta$ ). $\beta$ alloys have god ductility and toughness, but relatively low strength.

In spite of excellent corrosion resistance and good stability at relative high temperature, the current temperature limit of conventionally processed wrought and cast titanium alloys is $595{ }^{\circ} \mathrm{C}\left(1100^{\circ} \mathrm{F}\right)$. This limit is due mainly to long-term surface and bulk metallurgical stability problem. In order to improve this limit to $700{ }^{\circ} \mathrm{C}\left(1200{ }^{\circ} \mathrm{F}\right)-$ a temperature often attained in critical aluminum die casting applications, new alloy systems (like titanium-matrix composites, titanium aluminides, or powder metallurgy alloys) or advanced coatings must be developed.

\subsection{Copper Alloys}

The most important properties of copper alloys, the ones that make them to be chosen over other metals are good resistance to corrosion, excellent electrical and thermal conductivity, as well as strength, resistance to fatigue and ability to take a good finish [30].

Among the copper alloys, copper-beryllium ones have superior properties as far as concerning the ability to resist contact with molten aluminum, combined with a high 
strength given by the age hardening. Alloy $\mathrm{C} 17200$ (98Cu-1.9Be-0.2Co) for instance, can reach a tensile strength as high as $212 \mathrm{ksi}(1460 \mathrm{MPa})$ [31]. Copper-beryllium alloys are widely used for injection molding tools, cores and inserts in steel moulds [32]; Copper beryllium is considered the material of choice for plunger tips in aluminum die casting [33]. The hardening phase consists of spherical and uniformly dispersed beryllides $(\mathrm{Cu}, \mathrm{Co}) \mathrm{Be}$ in a matrix of equiaxed $\alpha-\mathrm{Cu}$, which tends to form bands of cellular precipitates at the grain boundaries at long aging times (over $8 \mathrm{~h}$ ) or high aging temperatures (above $600^{\circ} \mathrm{F}$ or $315^{\circ} \mathrm{F}$ ) [34].

Many efforts have also concentrated on the development of alloys containing fine dispersed particles. One of the limitations of most copper alloys containing fine dispersed particles is the lack of strength above $930^{\circ} \mathrm{F}\left(500{ }^{\circ} \mathrm{C}\right)$, due to the excessive coarsening of particles. In order to increase the operation temperature, the intermetallic precipitate must show good stability and coarsening resistance at high temperatures [35].

In spinodal decomposition hardenable $\mathrm{Cu}-\mathrm{Ni}-\mathrm{Sn}$ alloys, suitable thermochemical treatment may produce good combinations of high yield strength (as high as $1400 \mathrm{MPa}$, in $\mathrm{Cu}-9 \mathrm{Ni}-6 \mathrm{Sn}$ ) and fracture ductility. These alloys have been investigated and found as capable of replacing $\mathrm{Cu}-\mathrm{Be}$ alloys in certain applications [36,37]. The strengthening mechanism on aging involves the formation of a spinodal decomposition product, nucleation of an ordered phase and discontinuous precipitation at a later stage, with the appreciation that the age hardening of the $\mathrm{Cu}-9 \mathrm{Ni}-\mathrm{xSn}$ alloys is determined by the $\mathrm{Sn}$ content. 


\subsection{Refractory Metals and Alloys - Molybdenum and Tungsten}

Refractory metals are characterized by a high melting point, being prime candidates for high-temperature applications [28,38,39].

Molybdenum combines a high melting point $\left(4730^{\circ} \mathrm{F}, 2610^{\circ} \mathrm{C}\right)$ with outstanding high temperature properties, like strength retention after thermal cycling (high temperature cyclic strength) and high conductivity even at elevated temperature, besides creep, recrystallization, and softening resistance [28, 38-40]. Its applications are wide, from lighting and microelectronics industry (high purity molybdenum), to the die casting tools (molybdenum alloys, like TZM [45]). The high thermal conductivity, low coefficient of thermal expansion and low specific heat are extremely beneficial for the resistance to thermal shock and fatigue [39]. The high temperature strength properties of

molybdenum alloys (TZM) originate from solid solution strengthening by dissolution of the alloying elements and from dispersion strengthening by formation of spheroidal complex carbides [39].

Molybdenum alloys, especially TZM, have been used for critical cores and die inserts in aluminum, zinc, and copper die casting. It has been reported that TZM is able to practically eliminate soldering and heat checking [39]. 
The main disadvantage of molybdenum is its oxidation in air or other oxidizing atmospheres above $930{ }^{\circ} \mathrm{F}\left(500{ }^{\circ} \mathrm{C}\right)$, which becomes catastrophic above $1450{ }^{\circ} \mathrm{F}(790$ $\left.{ }^{\circ} \mathrm{C}\right)$. One product of oxidation is $\mathrm{MoO}_{3}$, which is very volatile and sublimes readily from the solid. It has been found that molten tin, aluminum, nickel, iron and cobalt severely attack molybdenum, unless is protected by an adequate coating $[28,41]$.

Tungsten has the highest melting point of any metal $\left(3410{ }^{\circ} \mathrm{C}\right.$, or $\left.6170{ }^{\circ} \mathrm{F}\right)$, very high density $\left(19.26 \mathrm{~g} / \mathrm{cm}^{3}, 0.696 \mathrm{lb} / \mathrm{in}^{3}\right)$, unusual high elastic modulus (414 GPa, 60x10 psi), and very low thermal expansion coefficient. These special properties, including the highest tensile strength of any metal above $1650{ }^{\circ} \mathrm{C}$ make it a principal candidate for high temperature applications such as aerospace propulsion and energy production $[28,42,43]$. Tungsten is consolidated to full density by solid-state sintering and mechanical working (wrought $\mathrm{P} / \mathrm{M}$ tungsten), liquid-phase sintering of powders, and chemical vapor deposition. Tungsten alloys can be grouped in [28]:

- solid-solution alloys, containing molybdenum (2-20 \%) or rhenium (1-25\%)dispersion-strengthened alloy (1-2 \% $\mathrm{ThO}_{2}$, or $\mathrm{W}$ - $\mathrm{Rh}$ alloys with $\mathrm{ThO}_{2}$ or $\mathrm{HfC}$ added) - heavy alloys (W-Ni-Cu or W-Ni-Fe), produced by liquid-phase sintering. W-Mo alloys are of interest because molybdenum helps refine the grain size of arc-cast tungsten. The heavy alloys seek to exploit, in most of the cases, the high density of the material. 


\section{RESULTS AND DISCUSSION}

Typical chemical composition of tested materials, and selected physical and mechanical properties of representative alloys from each group of materials tested are shown in Tables 1-5.

\subsection{Advanced Die Steels}

A list of recently evaluated H 13 and H 11 die steels is shown in Table 1 which indicates their supplier and usual composition. These steels have been tested by immersion in molten aluminum at 1350 degrees Fahrenheit to show the results of the total crack area and the average maximum thermal fatigue crack length in attached Figures 1 and 2. Examination of these charts shows that some of the materials behaved somewhat better than the control premium grade $\mathrm{H} 13$ processed by a fast quench and double temper. It is noted that the total crack area and the average maximum crack length in Thyssen 2344 shows some improvement over H13.

Some of the more recently developed steels have shown considerable improvement in thermal fatigue cracking and have changed the cracking mode from "corner cracks" to a "surface crack" behavior as indicated in Figure 3 where PG H13 shows early corner cracks and QRO 90 and Dievar show mostly surface cracks. The surface cracking has very limited depth and does not appear to produce thermal fatigue cracking that subjects the metal part to significant thermal fatigue damage. The 
composition of some of these steels is shown in Table 2 and the different crack modes after 15,000 immersion cycles in Figure 4.

The reasons for the improved behavior of these steels was investigated by the experimental procedures outlined in Figure 5. The cracking pattern was determined by identifying and measuring the crack length with the MSQ Image Analysis System. The pattern shown with this equipment is illustrated in Figure 6 and the reduced amount of carbides for these steels in Figure 7. The combined count of carbides in steels with surface cracks in the as-quenched condition is less than for steels that exhibit corner cracks. It has also been observed that these steels are more resistant to softening during the thermal fatigue testing process.

The differences in the number of carbides determined for these oil-quenched steels after austenizing at $1875^{\circ} \mathrm{F}$ is shown in Figure 8. The reduced amount of softening that occurs when these steels are tested for thermal fatigue resistance after quenching and tempering using the regular thermal fatigue tests is shown in Figure 9. It is apparent from this figure that significantly less softening occurs for both Dievar and TQ1 steel. Figure 10 shows the amount of corner cracks and surface cracks that were obtained for these alloys. The information in Figure 11 shows a marked difference between corner and surface cracks of premium grade H13 and QRO 90. QRO 90 is also much less subject to softening when tested in the thermal fatigue test as shown in Figure 12, apparently because of the lower chromium and higher molybdenum contents. The toughness of these 
steels shows that $\mathrm{H} 13$ has a room temperature value of 13 foot pounds compared to 23 foot pounds for Dievar. Other data shows the toughness of QRO 90 to be lower.

The results of these tests for these new types of die steels have shown that carbides are not as common in as-quenched Dievar, QRO-90 and TQ1. Steels with lower carbide content resist thermal fatigue cracking better. Steels that exhibit the best tempering resistance also exhibit the best resistance to cracking as further described in Figure 13. The cracks in the $\mathrm{H} 13$ specimen cut through the corners of the specimen whereas the cracks in the Dievar and QRO- 90 tests are very shallow and are only on one side of the corners with considerable improvement in thermal fatigue resistance. There is however anecdotal evidence of severe washout damage in gating areas of inserts made of Dievar that was not encountered previously in H13. A possible explanation would be that the fine surface cracks interfere with the flow of the molten metal resulting in excessive washout. This hypothesis has yet to be confirmed experimentally.

\subsection{Non-Ferrous Candidate Materials}

A list of many of the materials that have been tested are shown in Table 3(a)-(d). This list includes some refractory metals, nickel-base and copper-base materials. In addition to the refractory metals shown in Table 3(d), other groups of refractory metals tested are shown in Table 5. The thermal fatigue behavior for these materials is shown in Figure 14. It is apparent from this figure that some of these materials are more resistant to thermal cracking than $\mathrm{H} 13$. When the average maximum crack length is considered, as shown in Figure 15, some of these materials such as the Nybril compositions can be 
subject to an occasional long crack forming from the corners. However, the thermal fatigue cracking of some of these alloys is considerably less than for good quality $\mathrm{H} 13$. The refractory metals including those in Table 3(d) and Table 5 did not form any cracks in thermal fatigue testing.

While many of these copper and nickel alloys exhibit better thermal fatigue behavior than $\mathrm{H} 13$ as shown in Figures 16 and 17, these alloys can be subject to damage on corners of the specimen as shown in Figures 18 and 19. This damage occurs because of the high solubility of copper and nickel in the molten aluminum and can cause difficulty in their use as die materials. The thermal fatigue cracking pattern is affected by the processing method as illustrated in Figure 20. Wrought alloys exhibit straight cracks, while in cast alloys the cracks are jagged and tend to follow features in the microstructure such a segregated areas in the inter-dendritic zones.

Nickel-based superalloys evaluated in this study include 718, 286, 625 and 909. The chemical composition of these alloys is listed in Table 4. These alloys suffered from the same problem with previously described nickel-based alloys i.e. severe soldering and washout. Rather than being soluble, nickel-based alloys form intermetallics with molten aluminum. These hard, brittle compounds formed on the surface will crack readily and spall, resulting in a net loss of material as shown in Figure 21. When unprotected and overheated they will underperform at best. It should be noted that if adequately cooled to avoid or minimize intermetallic formation, nickel-based superalloys will outperform H13 in thermal fatigue resistance. Unfortunately, their thermal conductivity is on the low 
side, as illustrated in Figure 22. This leads to rather high temperatures at the surface, and especially at corners as shown in Figure 23. Of the superalloys evaluated, the 718 performed best, as demonstrated in Figure 24 .

It is noted that none of the refractory alloys show any tendency to thermal fatigue cracking. These refractory metals are listed in Tables $3 \mathrm{c}$ and 5 and are produced from tungsten or molybdenum by a number of different methods and compositions.

\subsection{Metal Matrix Composites and High Thermal Conductivity Alloys}

A metal matrix composite made from Ti-6Al-4V with titanium carbide particles was tested as a die material. This metal was inferior to $\mathrm{H} 13$ in thermal fatigue resistance as shown in Figure 25 and Figure 26. The matrix material was tested by itself in the soft condition but failed prematurely by gross-cracking as illustrated in Figure 27. This material is considered as a potential shot sleeve material for aluminum because of good resistance to soldering and low thermal conductivity.

High thermal conductivity alloys have been used in shot blocks as shown in Figure 29 and Figure 30. The rate of cooling of the biscuit in the shot block is substantially faster than for conventional steels as demonstrated by the cooling curves in Figure 31 . High thermal conductivity materials including the refractory metals can be considered for shot blocks or other inserts in the die where faster cooling is desirable as concluded in Figure 32. 
Three nitro-carburized coatings were applied on H13. The cross-sections in Figure 33 show the thickness and hardness of these coatings. The thermal fatigue performance is shown in Figures 34 and 35. In essence, the nitro-carburized coatings did not improve the thermal fatigue resistance; some even decreased it. It should be remembered however, that the main purpose of these coatings is to improve the soldering resistance. Sacrificing some thermal fatigue resistance to gain better soldering resistance may be a desirable compromise in some applications.

\section{SUMMARY}

The quality of die steels and their treatment continue to improve. This report contains information that has been presented and discussed with the Die Materials Committee at their regular three annual meetings. Some of the die steels exhibit small improvements compared to premium grade H13. However, other special die steels such as Dievar and QRO 90 have developed a different cracking pattern that has very limited corner cracks and mostly a fine crack pattern that is very shallow in depth and exhibits excellent thermal fatigue resistance.

The die materials that had both nickel and copper as a base metal stood up well in thermal fatigue resistance but exhibited solution at the corner of the specimen because of the higher solubility of the base metal. The refractory base molybdenum and tungsten 
alloys have excellent thermal fatigue resistance. Special high conductivity materials such as Brush Alloy 3 facilitate rapid solidification of the surrounding metal and can be used to increase the production rate of die castings. 


\section{REFERENCES}

1. Stern, M. Die-Casting Practice, McGraw-Hill Book Company (1930)

2. Kaye, A. Die Casting Metallurgy, Butterworth Scientific (1978)

3. Yan, M., Fan, Z. Durability of Materials in Molten Aluminum Alloys, Journal of Materials Science 36 (2001)

4. Wang, Y. Effect of Composition and Processing on the Thermal Fatigue and Toughness of high Performance Die Steels, Ph.D. Thesis, Case Western Reserve University (1997)

5. Bertolo, R.B. Fracture Toughness of Aluminum Die Casting Die Steels, Ph.D. Thesis, Case Western Reserve University, 1976

6. Failure Analysis and Prevention, ASM Handbook Vol. 11, $9^{\text {th }}$ Edition, American Society for Materials Publications, pp. 266-267

7. Toyoda, H. et al. "Thermal Fatigue Properties and Their Evaluation", Transactions ISIJ 25 (1985)

8. Dieter, G. Mechanical Metallurgy, McGraw-Hill (1986), pp. 430

9. Zuchovski, R. "Analysis of the Thermal Fatigue Process", Journal of Materials Testing and Technology 106 (2000)

10. Skelton, R.P. "Introduction to Thermal Shock", High Temperature Technology 8 No. $2(1990)$

11. Zhou, Q. Master Thesis, Case Western Reserve University (2001)

12. Wallace, J.F. "Thermal Conditions in the Die", Foundry 96 (1968)

13. Seth, B.B. "A Review of Die Casting Dies", Die Casting Engineer 16 (1972)

14. Bethge, K.; Munz, D.; Neumann, J. "Crack Initiation and Propagation Under Thermal Cyclic Loading", High Temperature Technology Vol. 8 No. 2 (1990)

15. Graham, R.R. Thermal Fatigue Mechanisms in Aluminum Die Casting Die Steel, Ph.D. Thesis, Case Western Reserve University (1978)

16. Das, S. K. Effect of Heat Treatment on the Thermal Fatigue Behavior and Fatigue Toughness of H13 Steel for Aluminum Die Casting Dies," Ph.D. Thesis, Case Western Reserve University (1981)

17. Sharp, H.J. Aluminum Pressure Die Casting Dies-Their Failure by Surface Cracking, Metal Industry 51 (1953)

18. Roberts, G.A.; Grobe, A.H. Service Failure of Aluminum Die Casting Dies, Metal Progress 69 (1956)

19. Lu, T.J., Fleck, N.A. The Thermal Shock Resistance of Solids, Acta Materialia Vol. 46, No. 13

20. Manson, S.S. Thermal Stress and Low Cycle Fatigue, McGraw-Hill (1966), pp. 2122,303

21. Campbell, I.E. (Editor- in-Chief) High Temperature Technology, John Wiley and Sons (1957), pp. 460-476

22. Weronski, A.; Hejwowski, T. Thermal Fatigue of Metals, Marcel Dekker, Inc. (1991), pp.118-124

23. Winter, M. WebElementsTM Periodic Table

24. Ratna, V., Sarma, D.S. Influence of Thermal Fatigue on the Microstructure of a Nibase Superalloy, Scripta Metallurgica et Materialia, Vol. 29 (1993) 
25. Properties and Selection: Stainless Steel, Tool Materials and Special-Purpose Metals-Superalloys, ASM Handbook Vol. 3, $9^{\text {th }}$ Edition, American Society for Materials Publications, pp. 225-227

26. Lal, R.B., Aggarwal M.D. A Study of Microstructural Characteristics of Ni-Based Superalloys at High Temperatures, NASA Technical Report No. AAMU-NAG-003 (1990)

27. Heat-Resistant Materials-Titanium and Titanium Alloys, ASM Handbook (1997), edited by J.R. Davis, pp. 347-357

28. Heat-Resistant Materials- Refractory Metals and Alloys, ASM Handbook (1997), edited by J.R. Davis, pp. 361-371

29. Titanium-A Technical Guide, ASM International (1988), edited by M.J. Donachie, Jr., pp. 3-5

30. Properties and Selection: Nonferrous Alloys and Pure Metals-Introduction to Copper and Copper Alloys, ASM Handbook Vol. 2, $9^{\text {th }}$ Edition, American Society for Materials Publications (1990), pp.239

31. Properties and Selection: Stainless Steel, Tool Materials and Special-Purpose Metals-Nonferrous Wear Alloys, ASM Handbook Vol. 3, $9^{\text {th }}$ Edition, American Society for Materials Publications, pp. 593

32. Rebelo J.C., Morao Dias A., Mesquita, R., Vassalo, P., Santos, M. An Experimental Study on Electro-Discharge Machining and Polishing of High-Strength Copper-

Beryllium Alloys, Journal of Material Processing Technology 103 (2000)

33. Properties and Selection: Stainless Steel, Tool Materials and Special-Purpose Metals-Die-Casting Dies, ASM Handbook Vol. 3, $9^{\text {th }}$ Edition, American Society for Materials Publications, pp. 543

34. Properties and Selection: Nonferrous Alloys and Pure Metals-Properties of Wrought Copper, ASM Handbook Vol. 2, $9^{\text {th }}$ Edition, American Society for Materials Publications (1990), pp. 303

35. Dadras, M.M., Morris, D.G. Examination of Some High-Strength, High-Conductivity Copper Alloys for High-Temperature Applications, Scripta Materialia, Vol. 38 No. 2 \{1998)

36. Ray, R.K., Chandra N., S., Devaraj, S., Precipitation and Recrystallisation in a Cu9Ni-6Sn Alloy, Scripta Metallurgica, Vol. 14 (1980)

37. The Structure and Low Temperature Strength of the Age Hardened Cu-Ni-Sn Alloys, Kratochvil, P. Mencl, J., Pesicka, J., Komnik, S.N., Acta Metallurgica Vol. 32 No. 9 (1984)

38. Tietz, T.E., Wilson, J.W. Behavior and Properties of Refractory Metals, Stanford University Press (1965)

39. Burman, R. Properties and Applications of Molybdenum, in 'Refractory Metals and Their Industrial Applications', Smallwood, R.E. (ed.)

40. Shi, H-J, Korn, C., Pluvinage, G. High Temperature Isothermal and

Thermomechanical Fatigue on a Molybdenum -based Alloy, Material Science and Engineering A247 (1998)

41. Properties and Selection: Stainless Steel, Tool Materials and Special-Purpose Metals-Refractory Metals, ASM Handbook Vol. 3, $9^{\text {th }}$ Edition, American Society for Materials Publications, pp. 321-329 
42. Schmunk, R.E., Korth, G.E., Ulrickson, M., Tensile and Low-Cycle Fatigue Measurement on Cross-Rolled Tungsten at 1505 K, Journal of Nuclear Materials, v 122-, (May 1983)

43. Mullendore, J.A., Tungsten: Its Manufacture, Properties, and Applications, in 'Refractory Metals and Their Industrial Applications', Smallwood, R.E. (ed.) 


\section{FIGURES}


TABLE 1: COMPOSITION OF H11 AND H13 STEELS (spec.)

\begin{tabular}{||c|c|c|c|c|c|c||}
\hline wt \% & P.G. H-13 & H-11 & W302(H13) & 2344(H13) & H-11 & H13 \\
\hline C & 0.40 & 0.49 & 0.39 & 0.40 & 0.38 & 0.40 \\
\hline Si & 1.00 & 0.90 & 1.00 & 1.00 & 1.00 & 1.00 \\
\hline $\mathbf{M n}$ & 0.35 & 0.30 & 0.40 & 0.25 & 0.40 & 0.35 \\
\hline $\mathbf{P}$ & 0.025 & 0.025 & 0.01 & 0.009 & $0.015 \mathrm{max}$ & 0.025 \\
\hline $\mathbf{S}$ & 0.001 & 0.05 & 0.002 & 0.001 & $0.005 \mathrm{max}$ & 0.001 \\
\hline $\mathbf{C r}$ & 5.25 & 5.0 & 5.10 & 5.3 & 5.2 & 5.25 \\
\hline $\mathbf{M o}$ & 1.50 & 1.3 & 1.30 & 1.4 & 1.3 & 1.50 \\
\hline $\mathbf{V}$ & 1.00 & 0.5 & 1.00 & 1.00 & 0.4 & 1.00 \\
\hline $\mathbf{C u}$ & 0.08 & & - & & & 0.08 \\
\hline $\mathbf{N i}$ & 0.15 & & - & 0.09 & 0.6 & 0.15 \\
\hline $\mathbf{W}$ & & & - & & & \\
\hline \hline
\end{tabular}




\section{TABLE 2: LIST OF CANDIDATE NEW STEELS}

\begin{tabular}{|l|c|c|c|c|c|c|c|c|c|c|c|c|c|c|}
\hline Alloy & $\mathrm{C}$ & $\mathrm{Mn}$ & $\mathrm{Si}$ & $\mathrm{S}$ & $\mathrm{P}$ & $\mathrm{Cr}$ & $\mathrm{Mo}$ & $\mathrm{V}$ & $\mathrm{Ni}$ & $\mathrm{Cu}$ & $\mathrm{W}$ & $\mathrm{Ti}$ & $\mathrm{Co}$ & Fe \\
\hline P.G. H13 & 0.40 & 0.35 & $\mathbf{1 . 0 0}$ & $\begin{array}{c}.005 \\
\max \end{array}$ & $\begin{array}{c}.025 \\
\mathrm{max}\end{array}$ & 5.25 & 1.50 & 1.00 & & & & & & Bal. \\
\hline Kind TQ1 & 0.35 & 0.43 & 0.4 & $\begin{array}{c}.001 \\
\max \end{array}$ & $\begin{array}{c}.01 \\
\max \end{array}$ & 5.2 & 1.8 & 0.55 & & & & & & Bal. \\
\hline $\begin{array}{l}\text { Uddeholm } \\
\text { QRO-90 }\end{array}$ & 0.37 & 0.63 & 0.3 & 0.001 & 0.015 & 2.46 & 2.22 & 0.84 & & 0.2 & & & & Bal. \\
\hline
\end{tabular}




\section{Table 3(a): Chemical Composition of Tested Nonferrous Materials}

\begin{tabular}{|c|c|c|c|c|c|c|c|c|c|c|c|c|c|c|c|}
\hline Alloy & $\mathrm{Ni}$ & $\mathrm{Cu}$ & $\mathrm{Be}$ & C & $\mathrm{Ti}$ & Co & $\mathrm{Zr}$ & $\mathrm{Fe}$ & Al & $\mathbf{v}$ & Sn & $\mathbf{w}$ & Mo & $\mathrm{Cr}$ & $\mathrm{Nb}$ \\
\hline $\begin{array}{c}\mathrm{Ni}-\mathrm{Be} \\
\text { (Nibryl 360) }\end{array}$ & bal & & $\begin{array}{l}1.85- \\
2.05\end{array}$ & & $\begin{array}{l}0.4- \\
0.6\end{array}$ & & & & & & & & & & \\
\hline $\begin{array}{c}\mathrm{Ni}-\mathrm{Be} \\
\text { (Nibryl CX) }\end{array}$ & bal & $10-15$ & $1-1.3$ & & $\begin{array}{l}0.4- \\
0.6\end{array}$ & & & & & & & & & & \\
\hline $\begin{array}{c}\mathrm{Ni}-\mathrm{Be} \\
\text { (Nibryl FX) }\end{array}$ & bal & $10-15$ & $\begin{array}{c}0.75- \\
1.3\end{array}$ & & $\begin{array}{l}0.4- \\
0.6\end{array}$ & & & & & & & & & & \\
\hline $\begin{array}{c}\mathrm{Ni}-\mathrm{Be} \\
(\mathrm{M} 220 \mathrm{C})\end{array}$ & $\begin{array}{l}\text { bal- } \\
\text { addit. }\end{array}$ & & $\begin{array}{l}1.8- \\
2.3 \\
\end{array}$ & $\begin{array}{l}0.3- \\
0.5 \\
\end{array}$ & & & & & & & & & & & \\
\hline Alloy $718^{*}$ & 50-55 & \begin{tabular}{c|}
$\max$ \\
0.3 \\
\end{tabular} & & $\begin{array}{l}\max \\
0.08 \\
\end{array}$ & $\begin{array}{c}0.65- \\
1\end{array}$ & $\max 1$ & & 17 & $\begin{array}{l}0.2- \\
0.8 \\
\end{array}$ & & & & $\begin{array}{l}2.8- \\
3.3 \\
\end{array}$ & $17-21$ & $4.75-5.5$ \\
\hline $\begin{array}{l}\text { Cu-Be } \\
\text { (Q-Max) }\end{array}$ & & bal & $\begin{array}{l}0.4- \\
0.7\end{array}$ & & & $\begin{array}{l}2.4- \\
2.7\end{array}$ & $\begin{array}{l}0.2- \\
0.3\end{array}$ & & & & & & & & \\
\hline $\begin{array}{l}\text { Cu15Ni8Sn } \\
\text { (ToughMet 3) }\end{array}$ & 15 & bal & & & & & & & & & 8 & & & & \\
\hline $\begin{array}{c}\text { Cu9Ni6Sn } \\
\text { (MoldMax XL) }\end{array}$ & 9 & bal & & & & & & & & & 6 & & & & \\
\hline $\begin{array}{l}\text { Mo Alloy } \\
\text { (TZM) }\end{array}$ & $\begin{array}{l}\max \\
.005\end{array}$ & & & $\begin{array}{l}0.01- \\
0.04\end{array}$ & $\begin{array}{l}0.4- \\
0.55\end{array}$ & & $\begin{array}{l}0.06- \\
0.12\end{array}$ & & & & & & 99.4 & & \\
\hline $\begin{array}{c}\text { W Alloy } \\
\text { (Anviloy 1150) }\end{array}$ & 4 & & & & & & & 2 & & & & 90 & 4 & & \\
\hline Ti6Al4V & & & & 0.044 & bal & & & 0.18 & 6.18 & 4.01 & & & & & \\
\hline TiC-Ti6Al4V & & & comp & osite, & $10 \% \mathrm{Ti}$ & $\mathrm{C}$ in $\mathrm{Ti} 6$ & AII $\mathrm{V} r$ & natrix & & & & & & & \\
\hline
\end{tabular}

\footnotetext{
* see Table 2 for the particular chemical composition of tested nickel superalloys specimens
} 
Table 3(b): Selected Physical Properties of Representative Nonferrous Materials Thermal Fatigue Tested

\begin{tabular}{|c|c|c|c|c|}
\hline Alloy & $\begin{array}{c}\text { Density } \\
\text { Ib/in }^{3}\end{array}$ & $\begin{array}{c}\text { Thermal Exp. } \\
\text { in/in.F }\end{array}$ & $\begin{array}{c}\text { Thermal Cond. } \\
\text { BTU.in/ft'.h.F }\end{array}$ & $\begin{array}{c}\text { Elastic Modulus } \\
\text { psi }\end{array}$ \\
\hline $\begin{array}{c}\text { Ni-Be } \\
\text { (Nibryl 360) }\end{array}$ & 0.3 & $8 \times 10^{-6}$ & 333 & $30 \times 10^{6}$ \\
\hline $\begin{array}{c}\text { Cu-Be (Q-Max-eq. } \\
\text { C17500) }\end{array}$ & 0.31 & $9.8 \times 10^{-6}$ & 1550 & $18 \times 10^{6}$ \\
\hline $\begin{array}{c}\text { Cu-Ni-Sn } \\
\text { (Moldmax XL) }\end{array}$ & 0.32 & $9.3 \times 10^{-6}$ & 450 & $17 \times 10^{6}$ \\
\hline $\begin{array}{c}\text { Alloy 718 } \\
\text { Mo }\end{array}$ & 0.29 & $7.2 \times 10^{-6}$ & 79 & $30.6 \times 10^{6}$ \\
\hline $\begin{array}{c}\text { (TZM 364 Stress } \\
\text { Relieved) }\end{array}$ & 0.36 & $3.3 \times 10^{-6}$ & 819 & $47 \times 10^{6}$ \\
\hline $\begin{array}{c}\text { W } \\
\text { (Anviloy 1150) }\end{array}$ & 0.62 & $2.9 \times 10^{-6}$ & 888 & $49 \times 10^{6}$ \\
\hline $\begin{array}{c}\text { CermeTiC10 } \\
\text { (10\%TiC-Ti6Al4V) }\end{array}$ & 0.16 & $5 \times 10^{-6}$ & 48.5 & $19 \times 10^{6}$ \\
\hline \begin{tabular}{c} 
H13 \\
\hline
\end{tabular} & 0.28 & $5.8-7.3 \times 10^{-6}$ & 171 & $30 \times 10^{6}$ \\
\hline
\end{tabular}


Table 3(c): Selected Room Temperature Mechanical Properties of Representative Nonferrous Materials Thermal Fatigue Tested

\begin{tabular}{|c|c|c|c|c|c|}
\hline Alloy & $\begin{array}{c}\text { Impact } \\
\text { ft.lb }\end{array}$ & $\begin{array}{c}\text { UTS } \\
\text { ksi }\end{array}$ & $\begin{array}{c}\text { Yield Strength } \\
\text { ksi }\end{array}$ & $\begin{array}{c}\text { Elongation } \\
\%\end{array}$ & $\begin{array}{c}\text { Hardness } \\
\text { HRC }\end{array}$ \\
\hline $\begin{array}{c}\text { Ni-Be } \\
\text { (aged Nibryl 360) }\end{array}$ & 20 & 205 & 170 & 6 & 35 \\
\hline $\begin{array}{c}\text { Cu-Be } \\
\text { (Q-Max) }\end{array}$ & 120 & 110 & $1-4$ & 23 \\
\hline $\begin{array}{c}\text { Cu-Ni-Sn } \\
\text { (Moldmax XL) }\end{array}$ & $10-15$ (CVN) & 110 & 100 & 4 & 30 \\
\hline $\begin{array}{c}\text { Alloy 718 } \\
\text { Mo } \\
\text { (TZM 364 Stress } \\
\text { Relieved) }\end{array}$ & 210 & 175 & 22 & 45 \\
\hline $\begin{array}{c}\text { W } \\
\text { (Anviloy 1150) }\end{array}$ & 2 (CVN) & 140 & 125 & $\operatorname{max~10}$ & 32 \\
\hline $\begin{array}{c}\text { CermeTic10 } \\
\text { (10\%TiC-Ti6Al4V) }\end{array}$ & & 145 & 135 & $\operatorname{max~3}$ & 35 \\
\hline H13 & $8-14(\mathrm{CVN})$ & $220-250$ & $180-200$ & $9-15$ & 35 \\
\hline
\end{tabular}


TABLE 3(d): LIST OF NON-FERROUS CANDIDATE MATERIALS

\begin{tabular}{|l|c|c|c|c|c|c|c|c|c|c|c|c|}
\hline Material & $\mathrm{C}$ & $\mathrm{W}$ & $\mathrm{Mo}$ & $\mathrm{Fe}$ & $\mathrm{Ni}$ & $\mathrm{Ti}$ & $\mathrm{Zr}$ & $\mathrm{Cu}$ & $\mathrm{Be}$ & $\mathrm{Cr}$ & $\mathrm{Nb}$ & $\mathrm{Sn}$ \\
\hline $\begin{array}{l}\text { CMW- } \\
\text { Anviloy1150 }\end{array}$ & & 90.00 & 4.00 & 2.00 & 4.00 & & & & & & & \\
\hline Kulite-Kuldie & & 90.00 & 4.00 & 2.00 & 4.00 & & & & & & & \\
\hline Allvac 718L & 0.01 & & 3.10 & 18.20 & 53.80 & 0.93 & & & & 17.90 & 5.06 & \\
\hline CSM-PM Mo & & & 100 & & & & & & & & & \\
\hline $\begin{array}{l}\text { Brush-QMAX } \\
\text { Copper Beryllium }\end{array}$ & & & & & 0.20 & & & Bal. & 2.00 & & & \\
\hline $\begin{array}{l}\text { Brush-Nybril 360 } \\
\text { Nickel Beryllium }\end{array}$ & & & & & Bal. & 0.50 & & & 2.00 & & & \\
\hline $\begin{array}{l}\text { Brush-Nybril-FX1 } \\
\text { Nickel Beryllium }\end{array}$ & & & & & Bal. & 0.50 & & 12.50 & 1.00 & & & \\
\hline $\begin{array}{l}\text { Brush NBCX } \\
\text { Nickel Beryllium }\end{array}$ & & & & & Bal. & 0.5 & & 12.5 & 1.2 & & & \\
\hline $\begin{array}{l}\text { Brush M220C } \\
\text { Nickel Beryllium }\end{array}$ & 0.4 & & & & Bal. & & & & 2.00 & & & \\
\hline $\begin{array}{l}\text { Brush ToughMet2 } \\
\text { Brush ToughMet3 }\end{array}$ & & & & & $\mathbf{9 . 0 0}$ & & & Bal. & & & & 6.00 \\
\hline
\end{tabular}


Table 4: Chemical Composition of Thermal Fatigue Tested Nickel Superalloys

\begin{tabular}{|c|c|c|c|c|c|c|c|c|c|c|c|}
\hline Alloy & $\mathbf{N i}$ & $\mathrm{Fe}$ & Co & Mo & $\mathbf{T i}$ & Cr & $\mathrm{Zr}$ & Cu & Al & Mn & $\begin{array}{c}\text { Nb } \\
+ \\
\mathbf{T a}\end{array}$ \\
\hline 286 & 25.5 & 55.5 & 0.05 & 1.2 & 2.1 & 14.4 & $\begin{array}{l}\max \\
0.01\end{array}$ & 0.08 & 0.2 & 0.24 & 0.02 \\
\hline 625 & 61.6 & 4.5 & 0.03 & 8.4 & 0.3 & 20.9 & 0.02 & 0.09 & 0.25 & 0.18 & 3.5 \\
\hline 718 & 54.2 & 18.5 & 0.02 & 2.9 & 0.9 & 17.7 & $\begin{array}{l}\max \\
0.01\end{array}$ & 0.03 & 0.5 & 0.04 & 5 \\
\hline 909 & 38 & bal & 14 & & 1.6 & $<0.5$ & & $\max _{0.5}$ & $\begin{array}{l}\max \\
0.15\end{array}$ & $\max _{0.5}$ & 49 \\
\hline
\end{tabular}


Table 5: Refractory Metals Evaluated in the Program

\begin{tabular}{|l|l|l|l|}
\hline Designation & Supplier & Composition & Processing \\
\hline Anviloy 1150 & CMW & $90 \mathrm{~W} ; 4 \mathrm{Ni} ; 2 \mathrm{Fe} ; 4 \mathrm{Mo}$ & Sintered \\
\hline K1705 & Kulite Tungsten Co. & $90 \mathrm{~W} ; 4 \mathrm{Ni} ; 2 \mathrm{Fe} ; 4 \mathrm{Mo}$ & As-sintered \\
\hline K1705 & Kulite Tungsten Co. & $90 \mathrm{~W} ; 4 \mathrm{Ni} ; 2 \mathrm{Fe} ; 4 \mathrm{Mo}$ & Heat treated \\
\hline Diemitech & Kulite Tungsten Co. & $92 \mathrm{~W} ; 4 \mathrm{Mo} ; \mathrm{Fe}+\mathrm{Ni}$ Bal. & Sintered \\
\hline TZM & CSM Eng. & $\mathrm{Mo} ; 0.5 \mathrm{Ti} ; 0.1 \mathrm{Zr}$ & Arc melted \\
\hline TZM & CSM Eng. & $\mathrm{Mo} ; 0.5 \mathrm{Ti} ; 0.1 \mathrm{Zr}$ & Arc Melted \\
\hline SMHC & CSM Eng. & $\mathrm{Mo}+\mathrm{HfC}$ & Sintered \\
\hline
\end{tabular}


FIGURE 1: TOTAL CRACK AREA AFTER 15,000 THERMAL FATIGUE CYCLES




FIGURE 2: AVERAGE MAXIMUM CRACK LENGTH

AFTER 15,000 THERMAL FATIGUE CYCLES

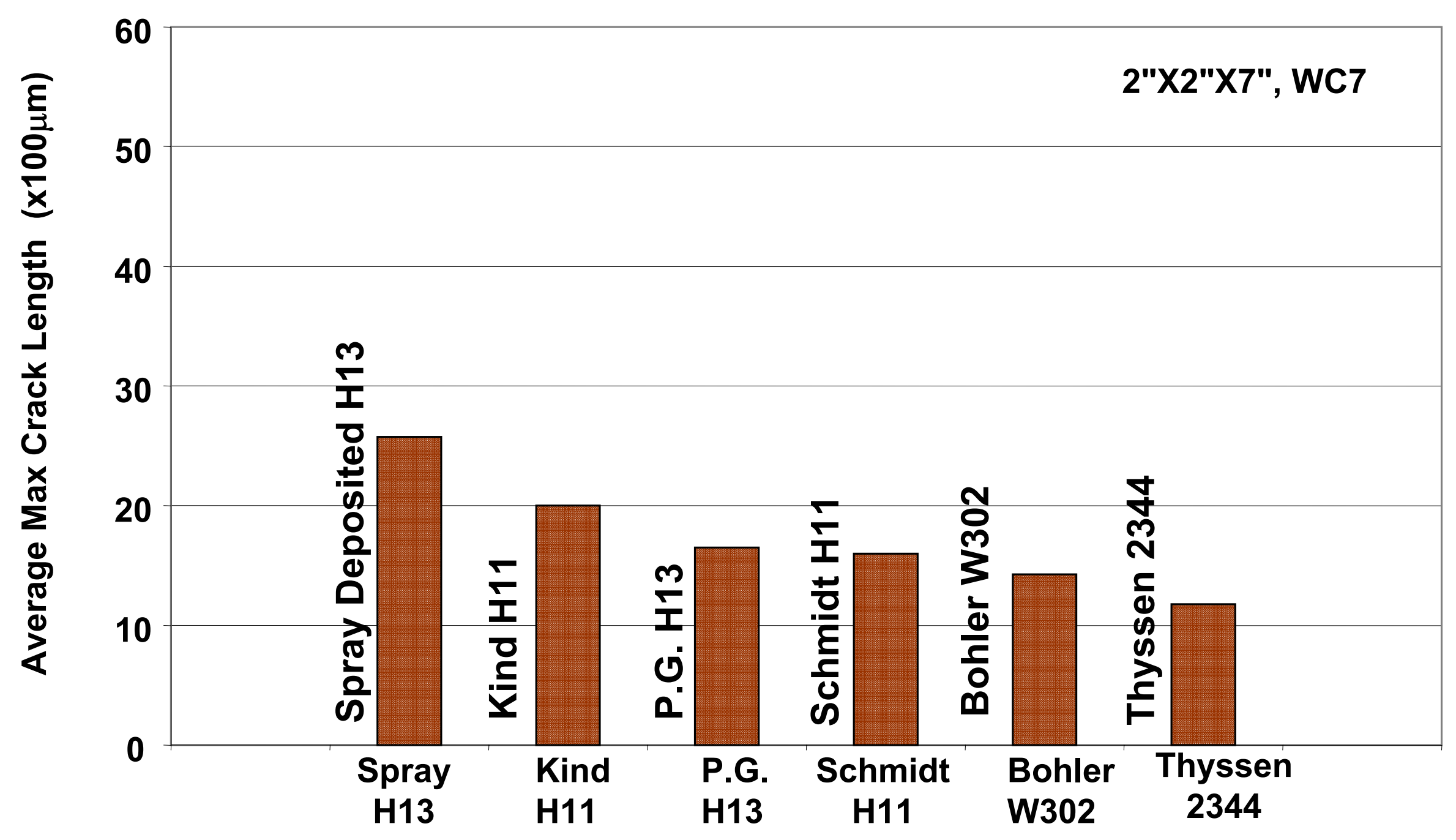




\section{Figure 3: SURFACE VS. CORNER CRACKS}

During thermal fatigue evaluation of die steel specimens two kinds of cracks are observed:

1. Corner Cracks - cut deep through the specimen corner; visible on both sides of the corner.



Among the recently evaluated steels:

- P.G. H13 shows mostly corner cracks

- QRO 90 and Dievar show mostly surface cracks

- TQ-1 shows some corner and mostly surface cracks 
Figure 4: Thermal Fatigue Cracks in New Die Steels (15,000 Cycles)

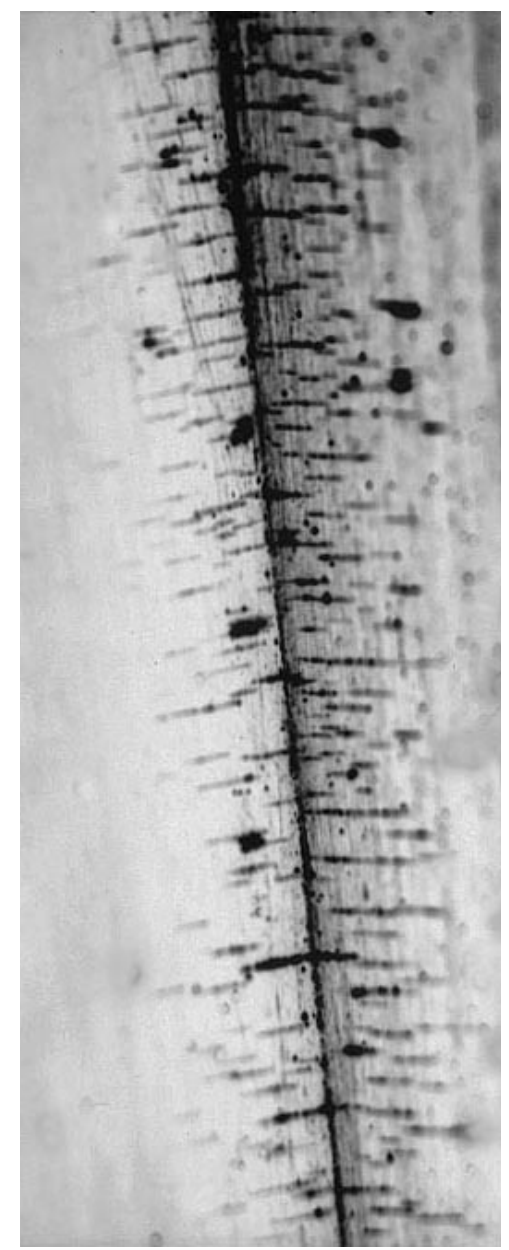

DIEVAR

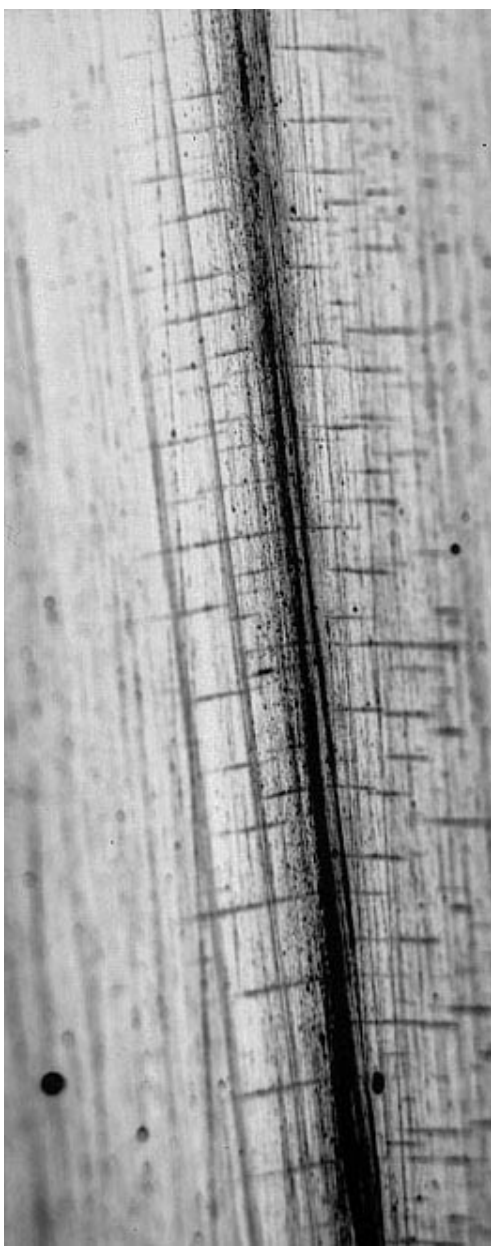

QRO90



TQ1

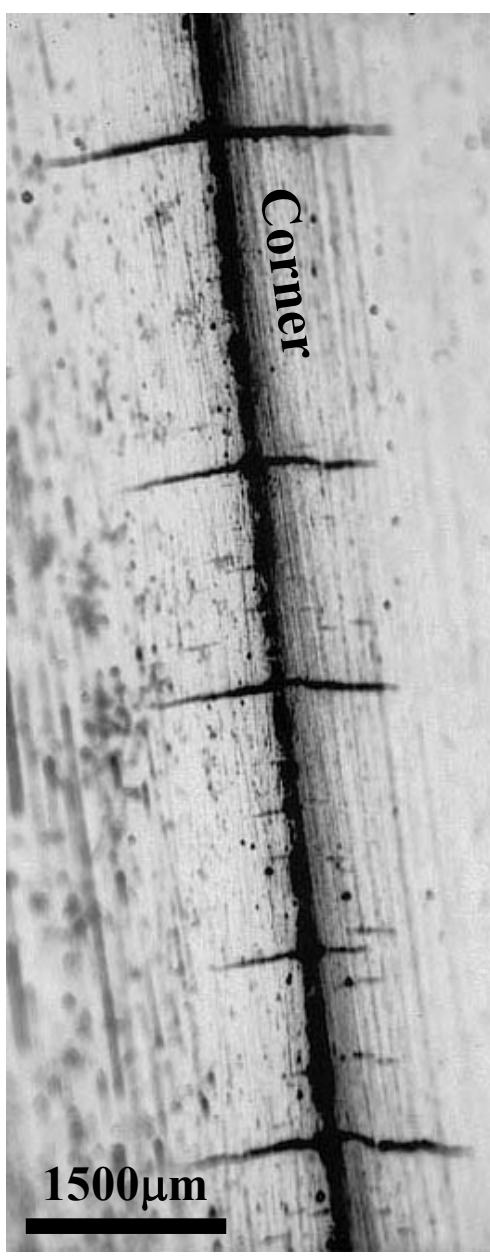

P.G.H13

Mostly surface cracks Mostly corner cracks 


\section{Figure 5: EXPERIMENTAL PROCEDURE}

In attempt to assess the source and relative weight of corner and surface cracks, the following experiments were conducted:

1. Carbide count in the as-oil quenched condition for these steels with the MSQ Image Analysis System.

2. Softening at the thermal fatigue sample corner by microhardness testing after 5,$000 ; 10,000 ; 15,000$ cycles.

3. Total Corner Crack Area and Maximum Crack Length utilizing the MSQ Image Analysis System. 

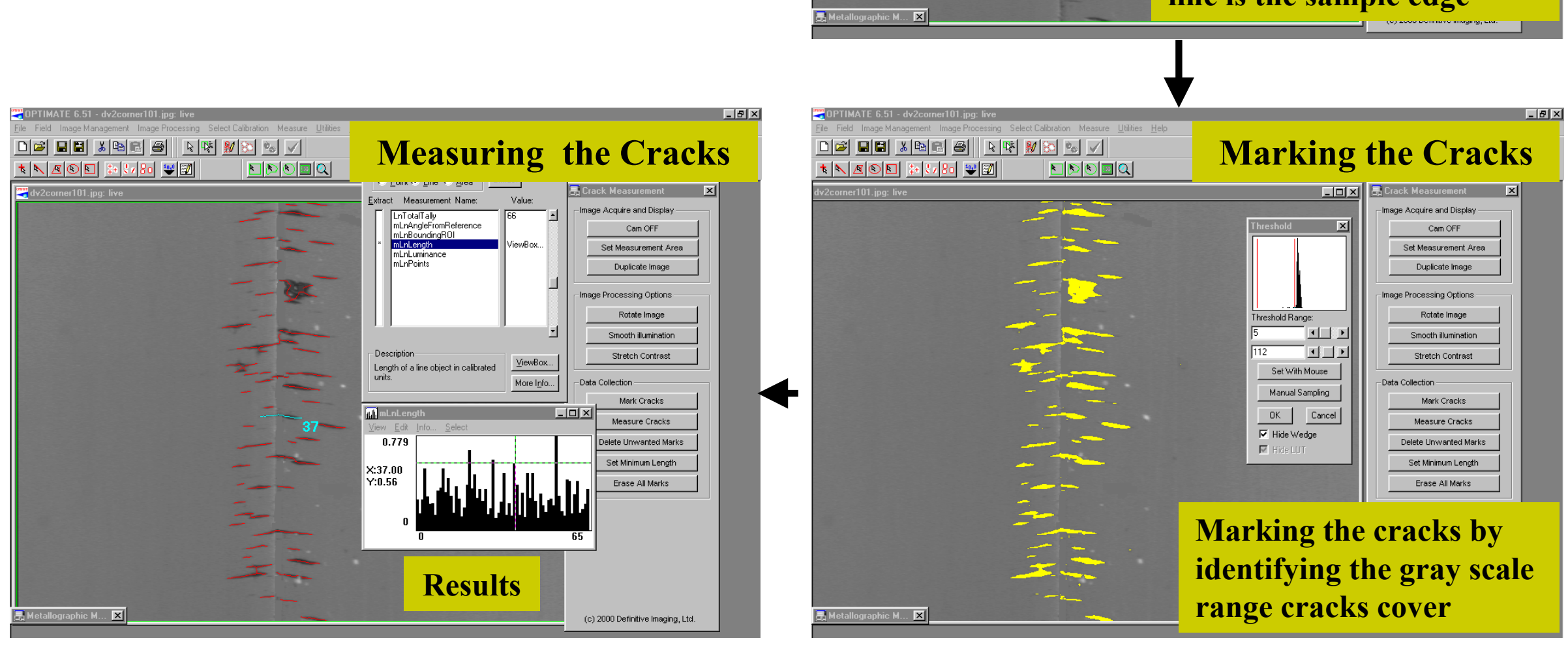


\section{Figure 7: SEM Micrograph - Austenitized @ $1875^{\circ} \mathrm{F}$ for 30min. and Oil-quenched}
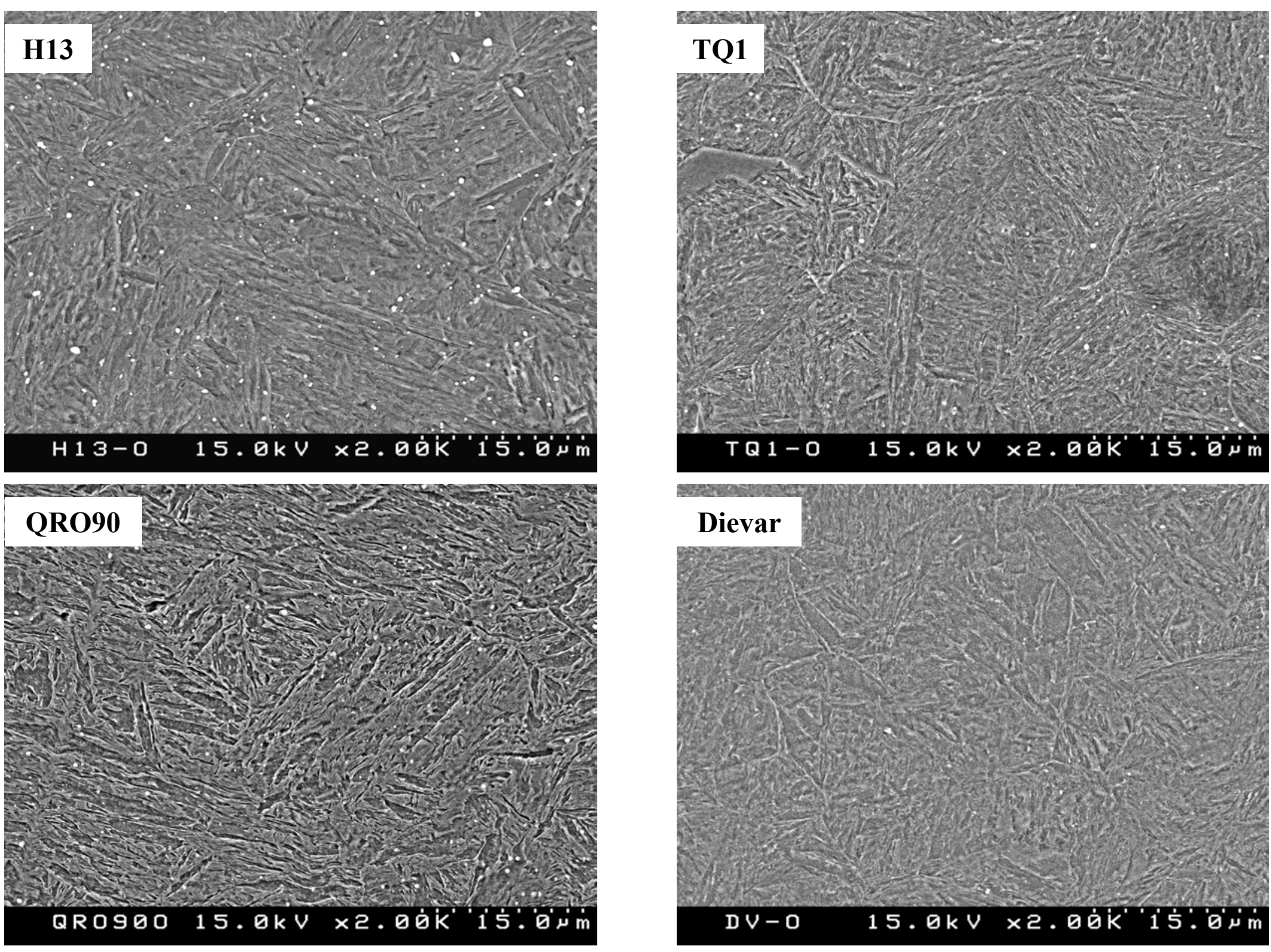


\section{Figure 8: Number of Carbides* in Oil-quenched Die Casting Die Steels}



* Per square inch; measured with MSQ Image Analysis System 


\section{FIGURE 9: SOFTENING AFTER 15,000 THERMAL FATIGUE CYCLES}

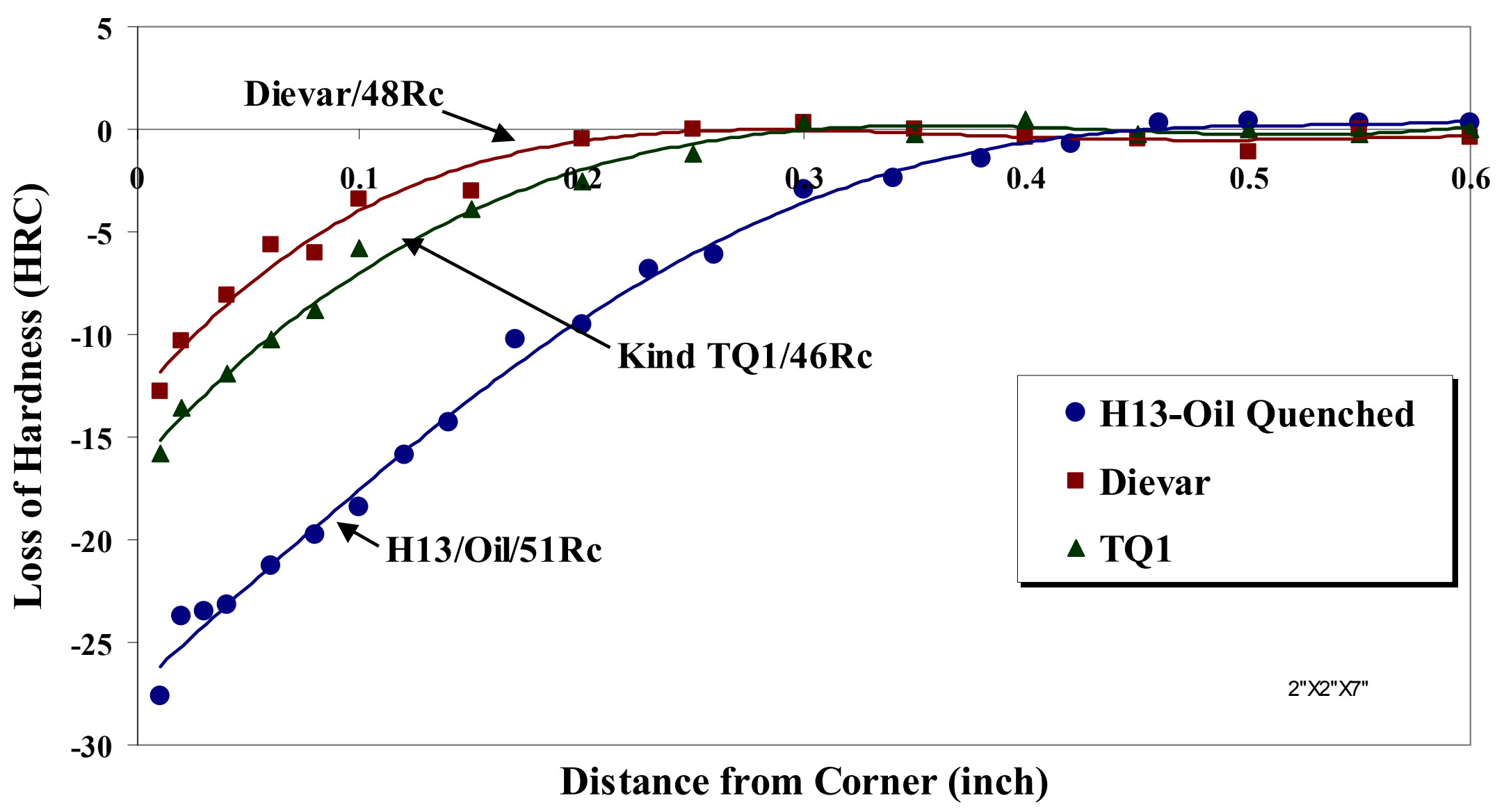

Dievar and TQ1 have better tempering resistance than P.G. H13. 


\section{Figure 10: Average Maximum Crack Length}

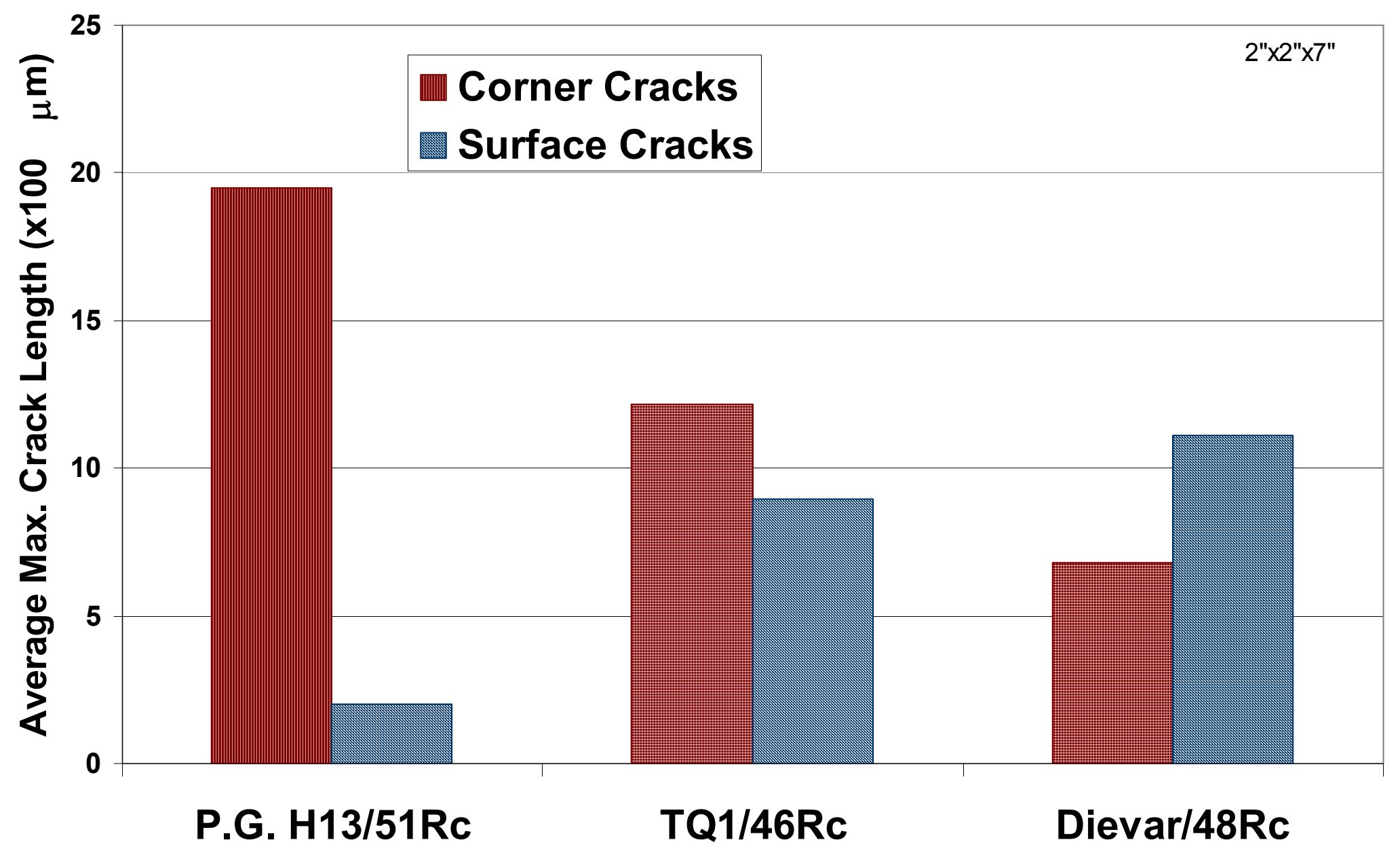




\section{Figure 11: Average Maximum Crack Length}






\section{FIGURE 12: SOFTENING AFTER 15,000 THERMAL FATIGUE CYCLES}



QRO90 have better tempering resistance than P.G. H13. 


\section{Figure 13: PRESENT CONCLUSIONS - 1}

1. The carbides in as-quenched Dievar, QRO-90 and TQ1 are fewer and smaller than in P.G. H13.

2. Dievar, QRO-90 and TQ1 have better tempering resistance than P.G. $\mathrm{H13}$ as demonstrated by the softening of the corners in the thermal fatigue specimens.

3. In P.G.-H13 specimens the thermal fatigue cracks are deeper and cut through the corners; in Dievar and QRO 90 the cracks are shallow and only on one side of the corners. TQ-1 has a mixed mode of cracks.

4. A high tempering resistance is a good indicator of superior thermal fatigue resistance. It demonstrates less of a tendency of the carbides to coarsen and deplete the matrix from alloying elements. The coarser carbides typical to softening may also promote fatigue crack propagation leading to the deeper corner cracks.

5. Dievar, QRO-90 and TQ1 show more thermal fatigue resistance than P.G. H13 in the dunk test. Field testing is required to further confirm these findings. 


\section{FIGURE 14: TOTAL CRACK AREA AFTER 15,000 THERMAL FATIGUE CYCLES (1"x1"x7")}






\section{FIGURE 15: AVERAGE MAXIMUM CRACK LENGTH AFTER 15,000 THERMAL FATIGUE CYCLES (1"x1"x7")}

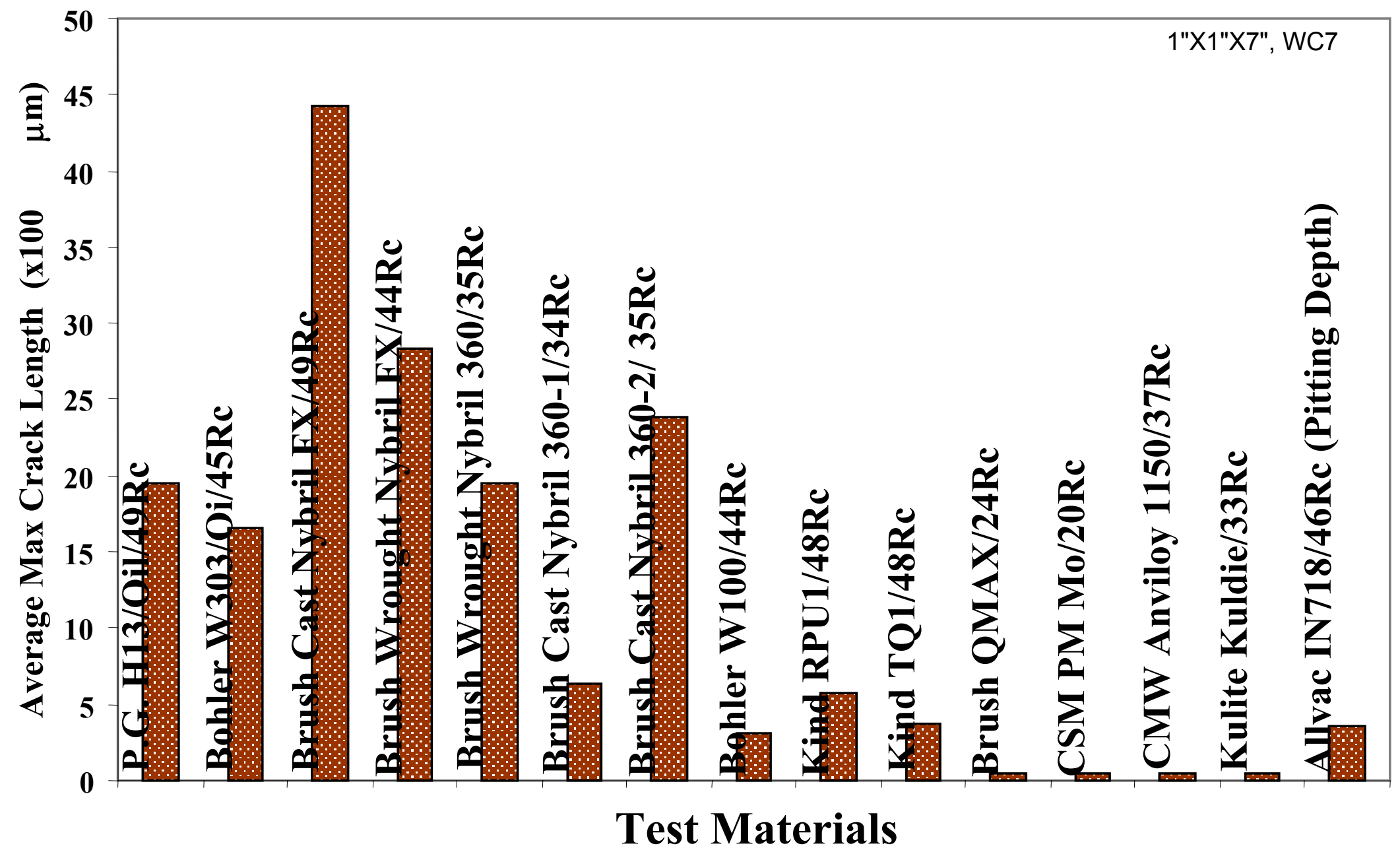




\section{Figure 16: Total Crack Area}

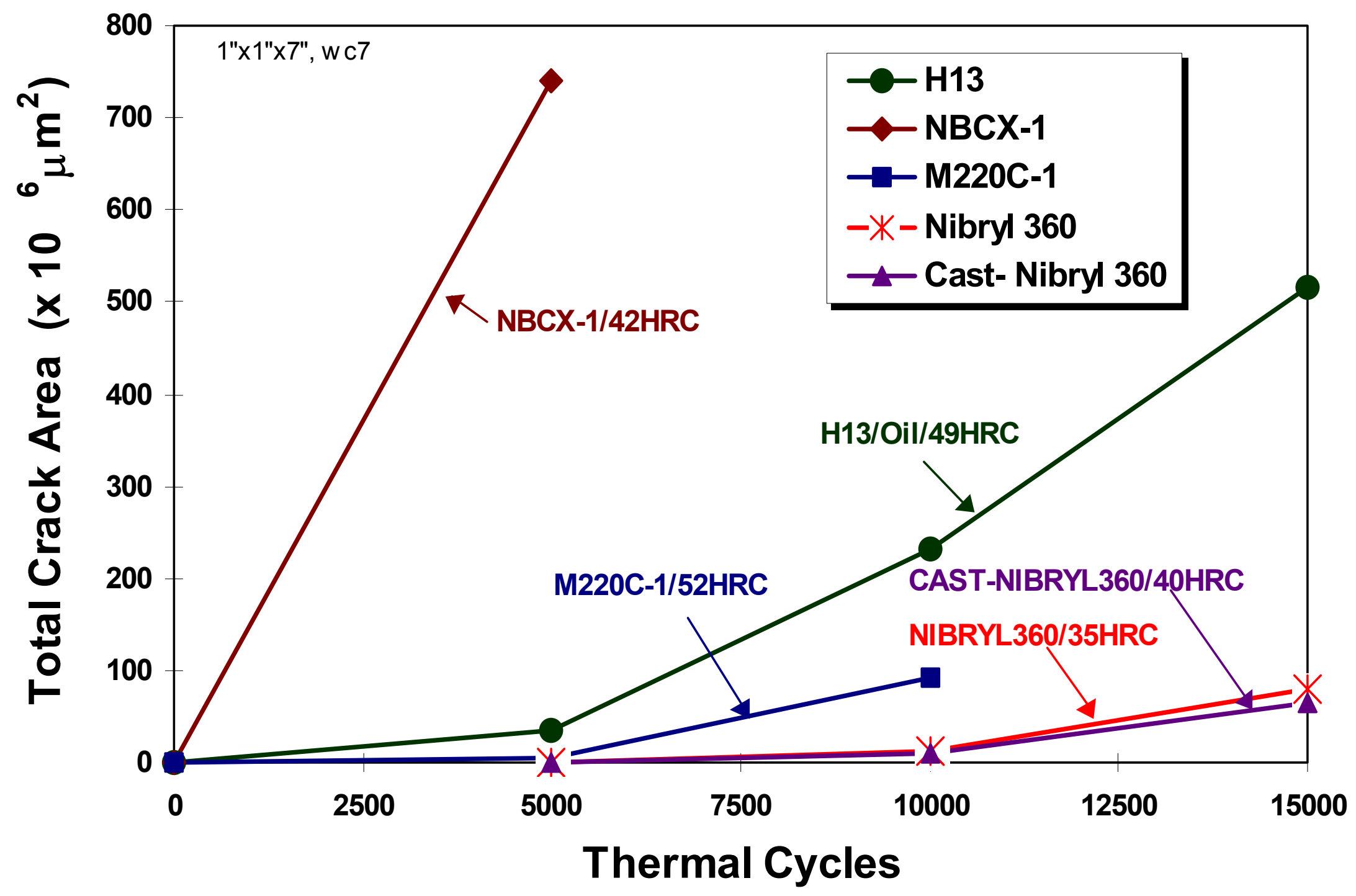




\section{Figure 17: Average Maximum Crack Length}




Figure 18: Soldering Damage at the Corners of Cu-Ni-Sn Thermal Fatigue Specimens

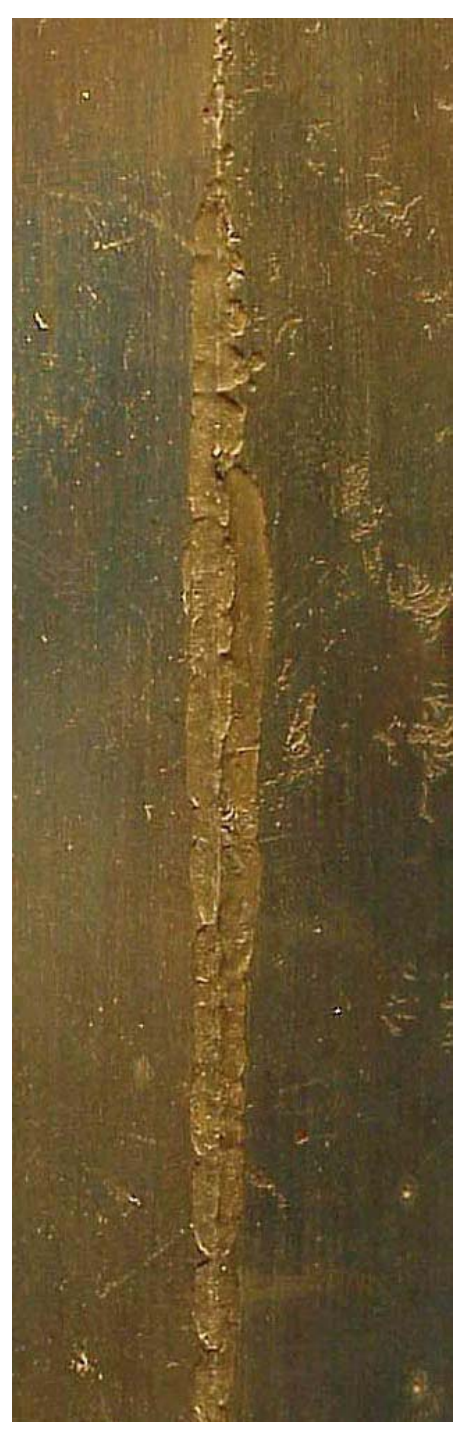

ToughMet 3



ToughMet 2



ToughMet 2

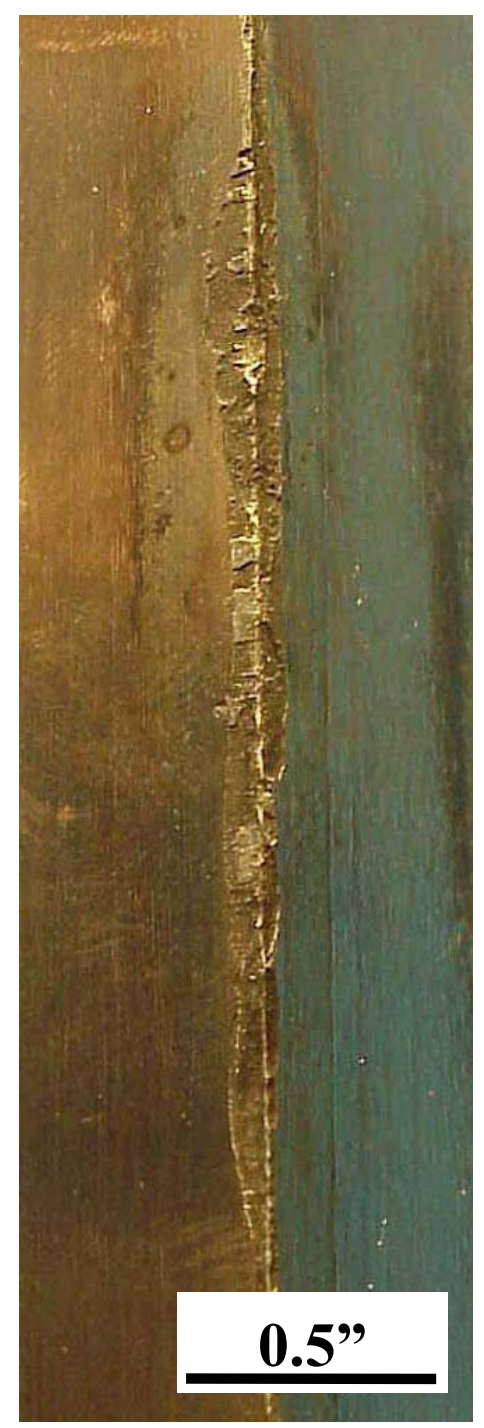

ToughMet 2 


\section{Figure 19: Thermal Fatigue Damage in NBCX-1 and M220C-1}
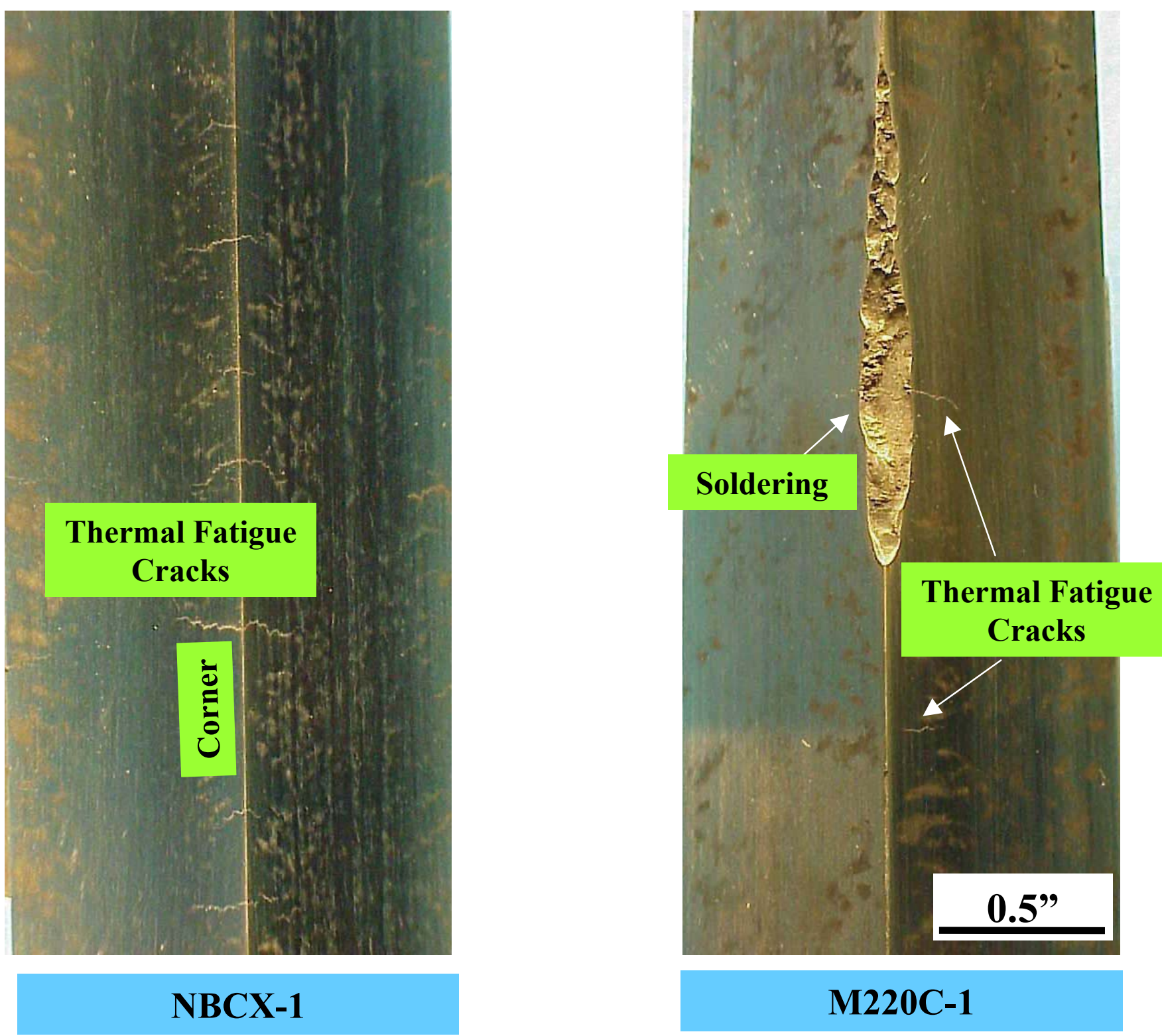
Figure 20:Cracking at the Corners of 1x1x7 Ni-Be Specimens After 15,000 Cycles
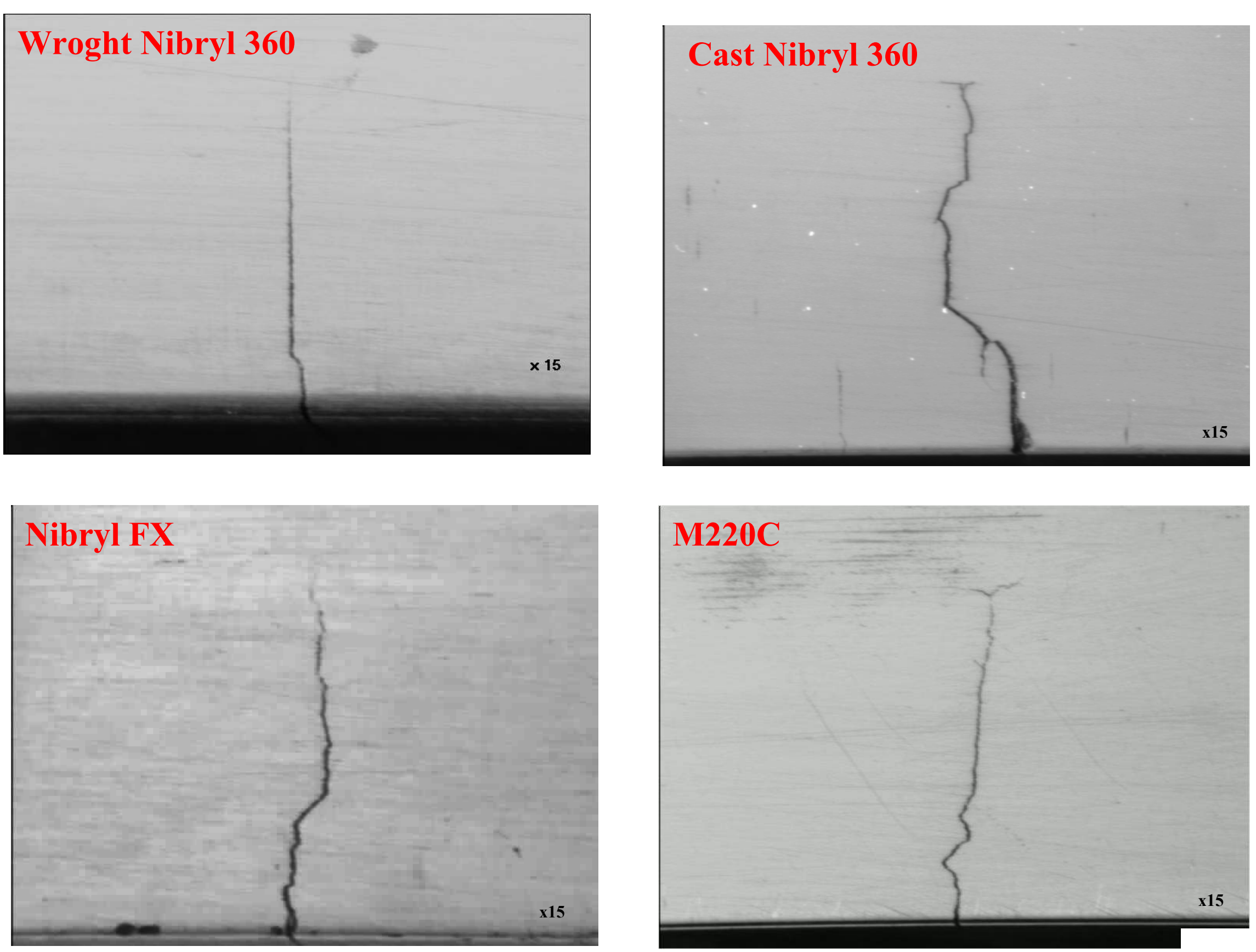
Figure 21:Dissolution at the Corners of Nickel Superalloys $2 \times 2 \times 7$ Specimens After 15,000 Cycles
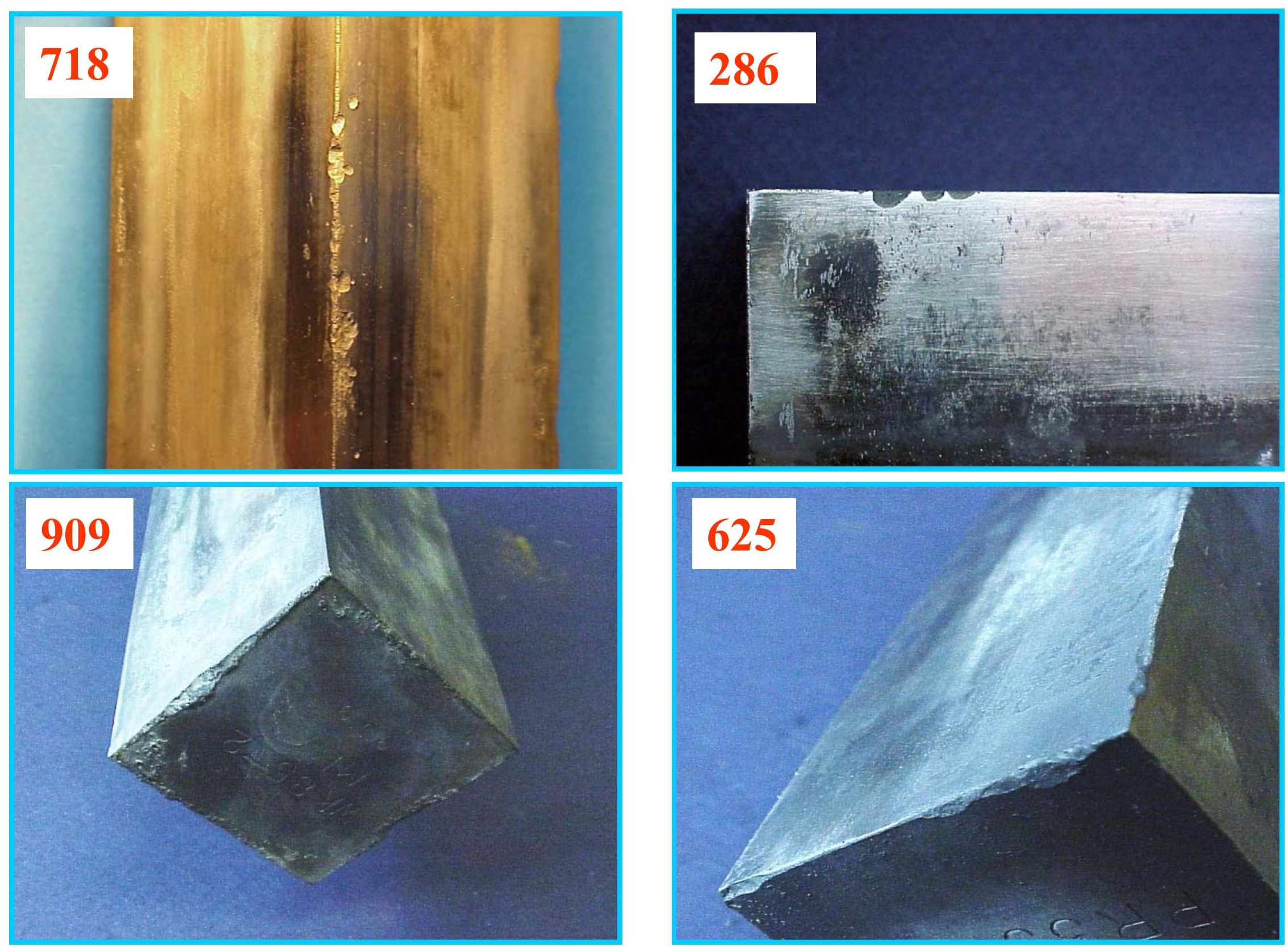
Figure 22:Thermal Conductivity Coefficients of Evaluated Nonferrous Materials

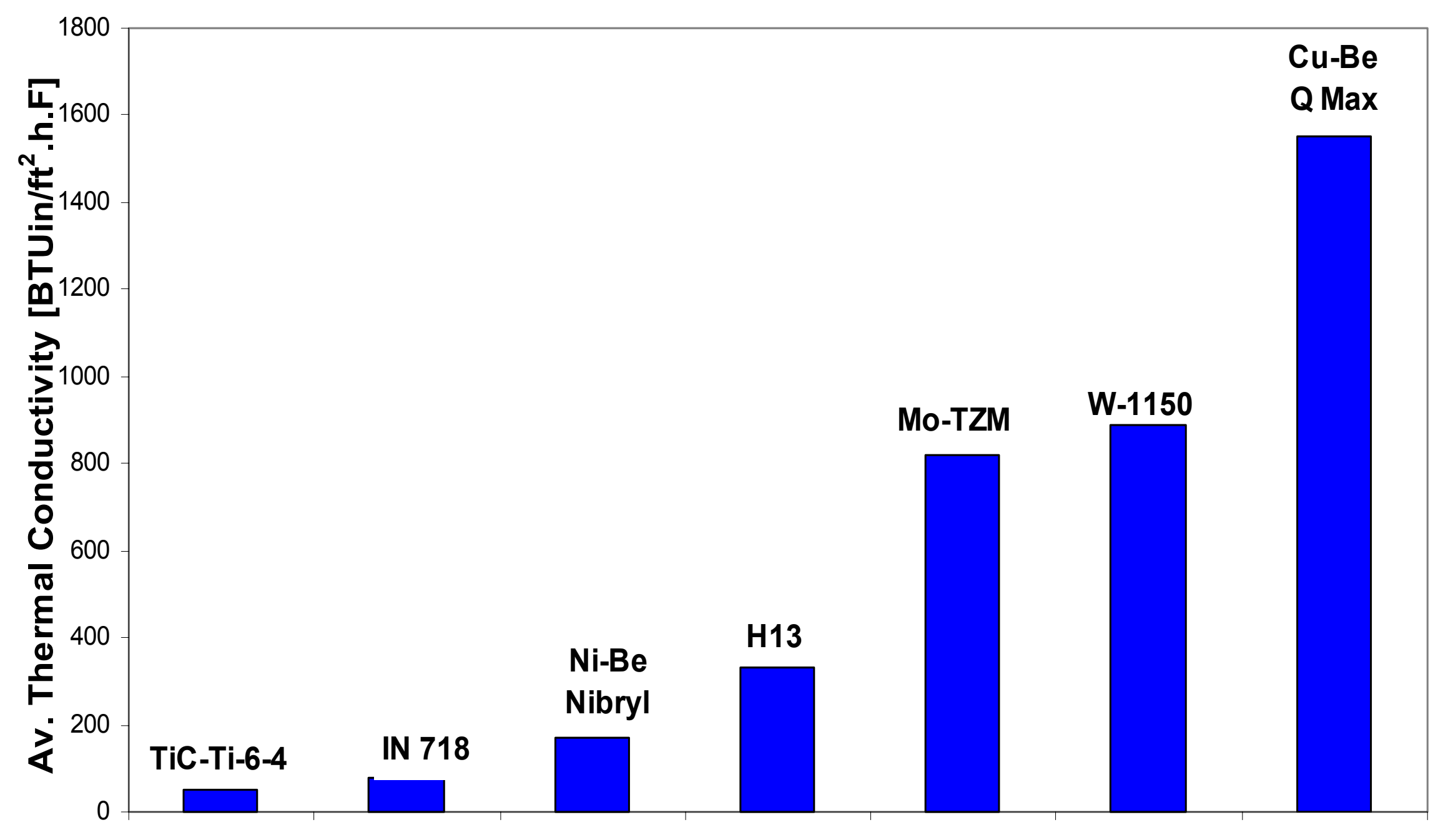


Figure: 23: Corner Temperature of Evaluated Nonferrous Materials




Figure 24:Average Maximum Pit Depth of Selected Superalloys

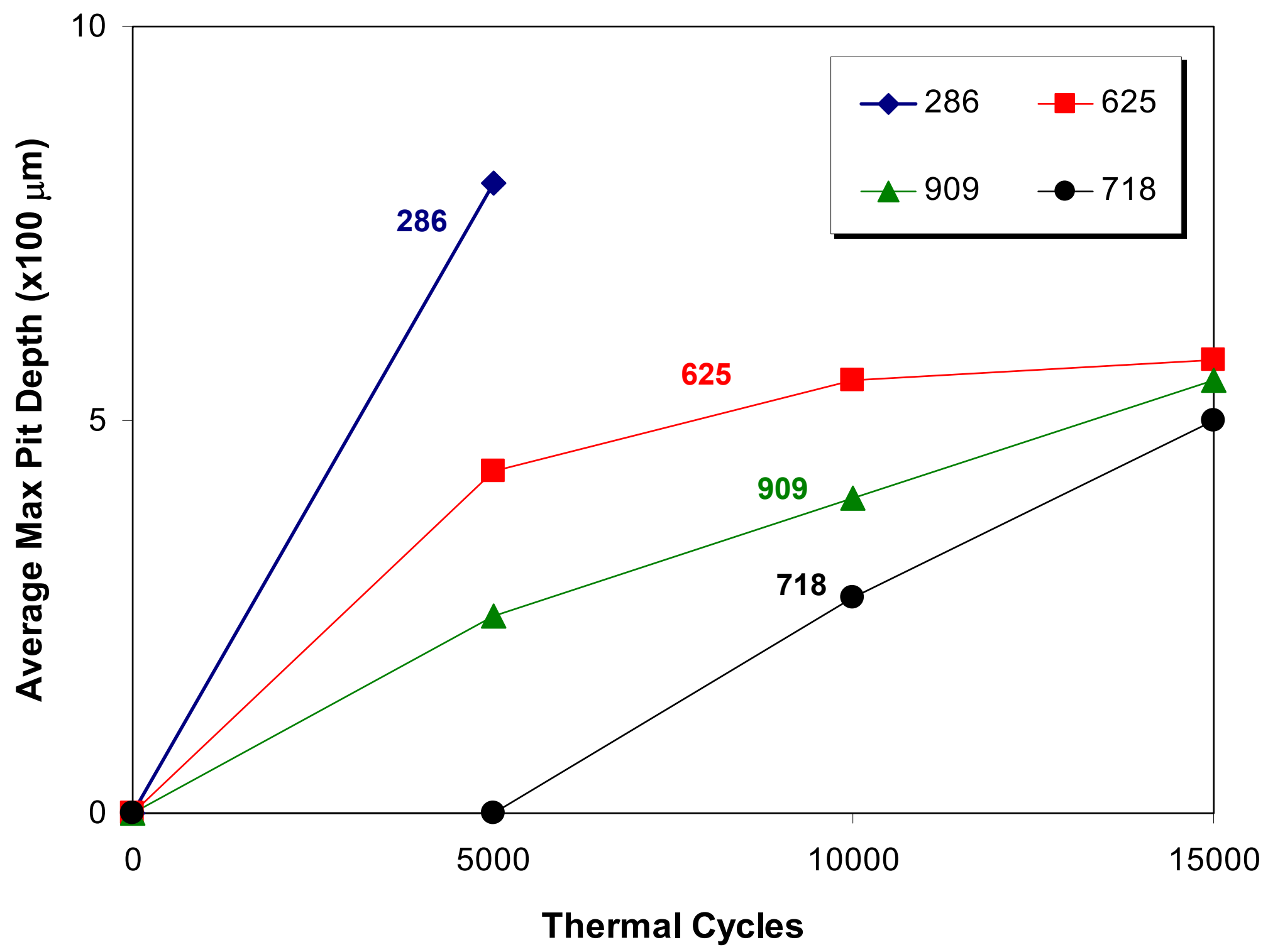




\section{Figure 25: CermeTi - Titanium Metal Matrix Composite}

Composition: matrix Ti-6Al-4V + 10wt\% TiC particles.

Manufacturing: by PM at Dynamet, Burlington MA.

Main application: Liner for shot sleeves.

Advantages: Low thermal conductivity

(5.9 W/mK that is ca. $25 \%$ of $\mathrm{H} 13$ )

Good resistance to soldering and dissolving in molten Al

Good wear resistance (@40HRC) 
FIGURE 26: AVERAGE MAXIMUM CRACK LENGTH OF CermeTi-C-10 vs. H13

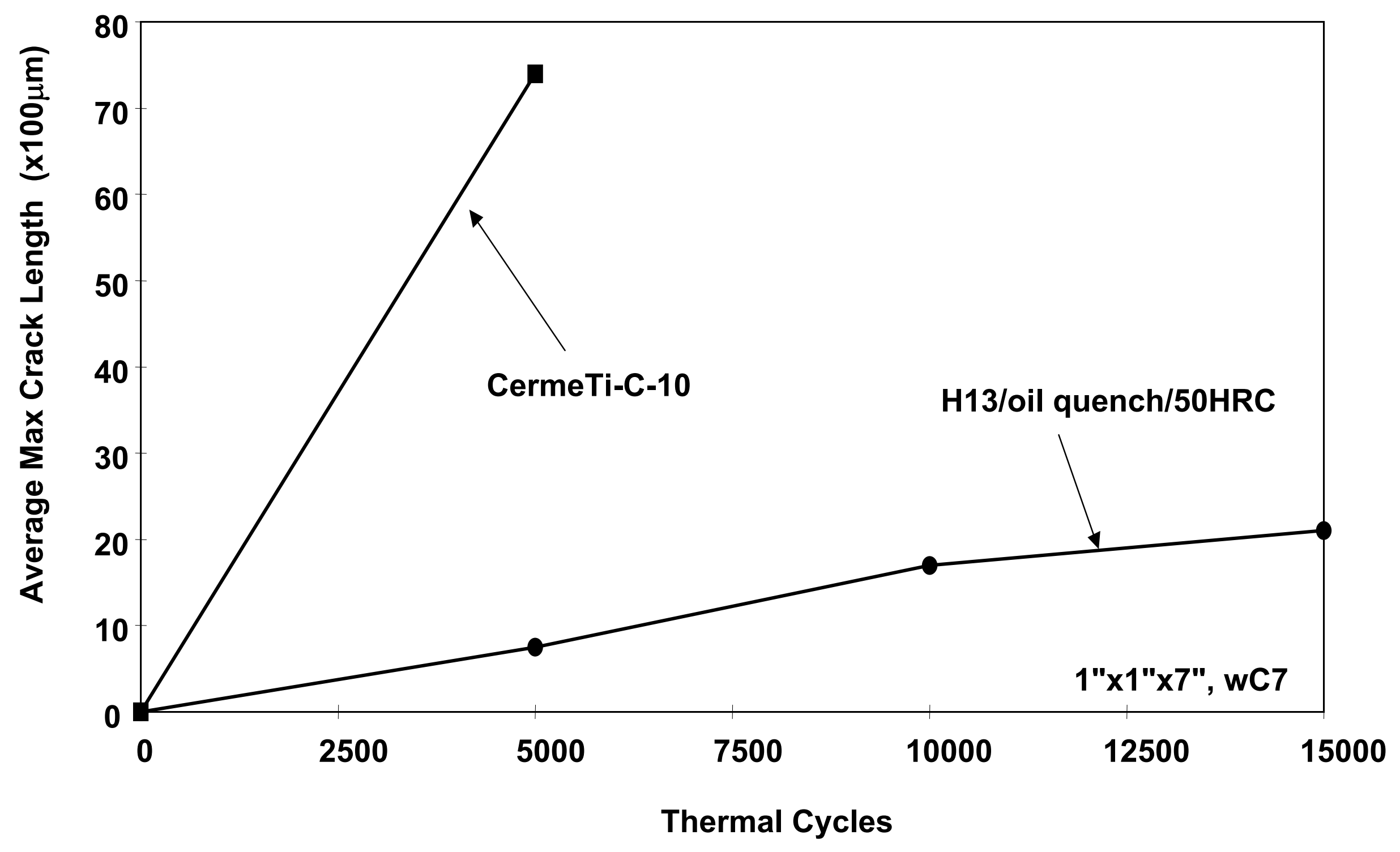


Figure 27:Longitudinal and Corner Cracks on Ti6Al4V and 10\% TiC-Ti6Al4V

\section{Ti6Al4V}

was ary

\section{0\%TiC-Ti6Al4V}

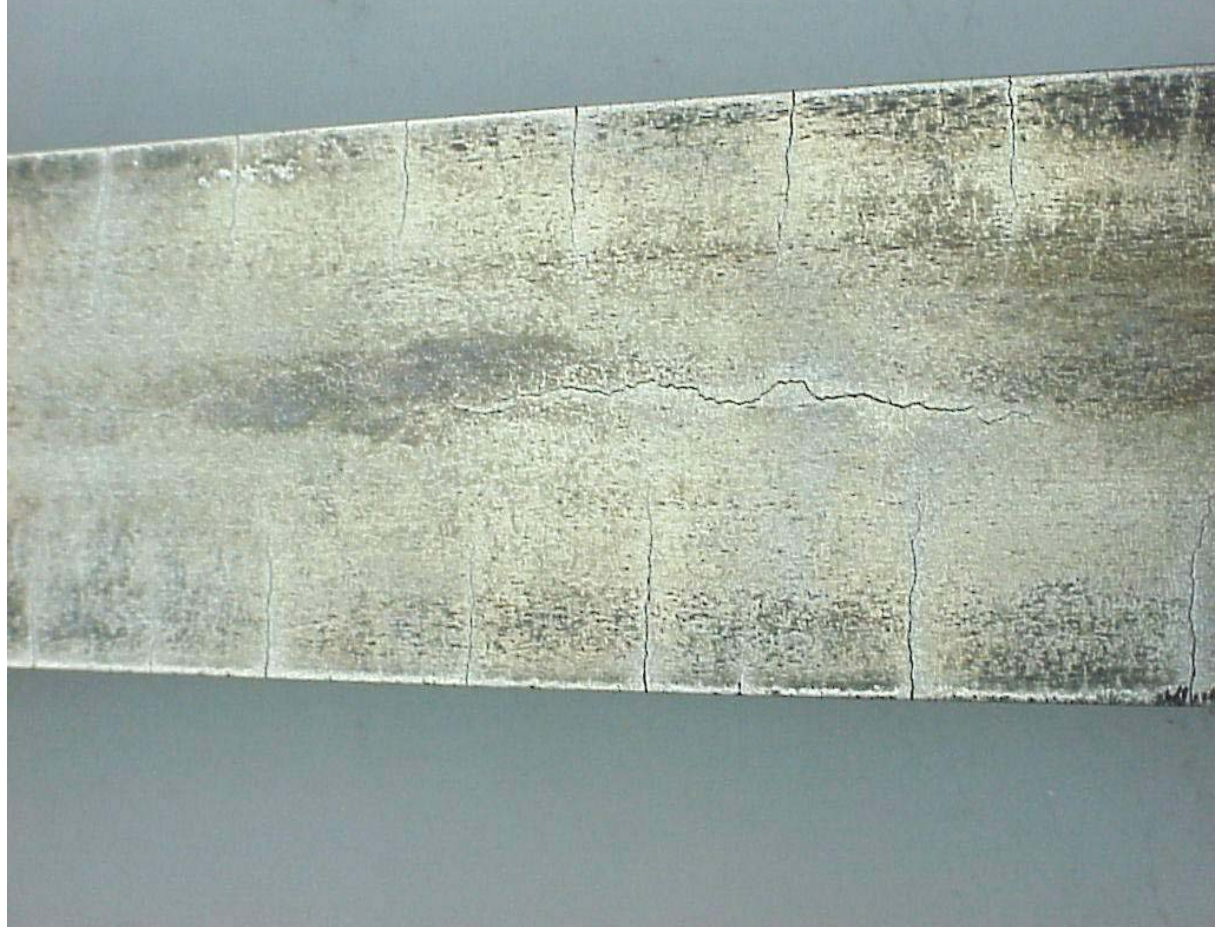




\section{Figure 28: INCREASING PRODUCTIVITY WITH SHORTER CYCLES}

\section{METHOD:}

- Utilize high thermal conductivity materials to extract heat faster from the large cross sections.

\section{EXPERIMENTAL}

- Shot blocks made of H13, Brush Alloys C3 (copper-base), Mold Max, Mold Max XL and CMW Anvilloy (W base)

- Record cooling curve of the biscuit.

- Determine "Die Open" time for different shot block materials.

\section{$\underline{\text { RESULTS }}$}

"Die Open" time (@950F)for Brush Alloy C3 is $18.2 \mathrm{sec}$. vs. $28.6 \mathrm{sec}$. for H13. This is a $36 \%$ reduction in cycle time. 


\section{Figure 30: Shot Block}




Figure 31: Cooling Curves in the Biscuit with Copper-based, Anvilloy \& Steel Shot Blocks

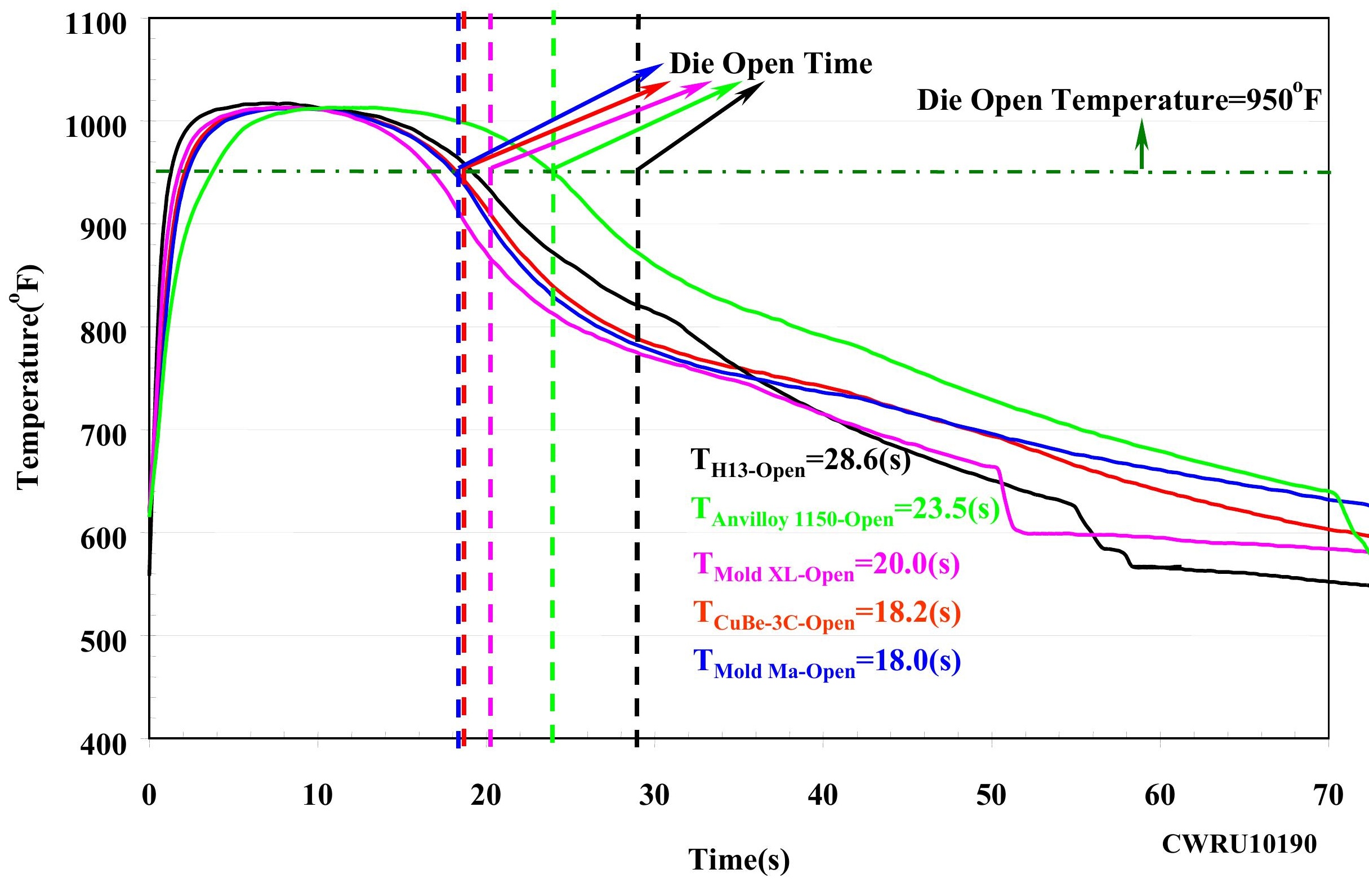




\section{Figure 32: PRESENT CONCLUSIONS - 2}

- Many copper and nickel based alloys have better thermal fatigue resistance than P.G. H13. However, these alloys tend to dissolve or react with aluminum alloys more than die steels.

- Refractory metals did not crack at all in the thermal fatigue test.

- These alloys have been used in shot blocks. The cooling rate of the biscuit in these shot blocks was substantially higher than with steel shot blocks. This method can be used to increase production rate in die casting. 


\section{Figure 33: Nitrocarburized H13 Layers}

Figure 34: Total Crack Area of Nitrocarburized H13

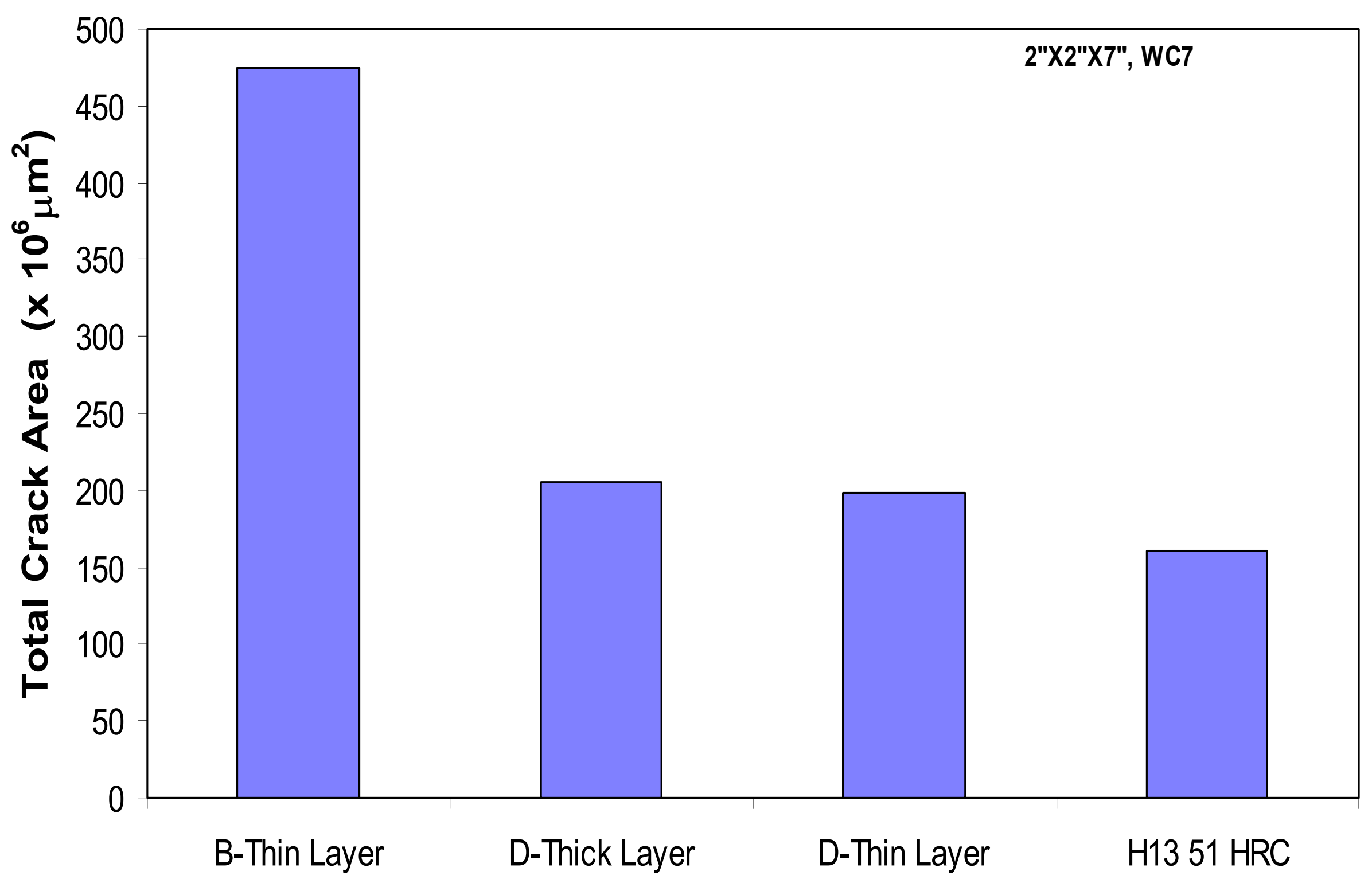


Figure 35: Average Maximum Crack Length of Nitrocarburized H13

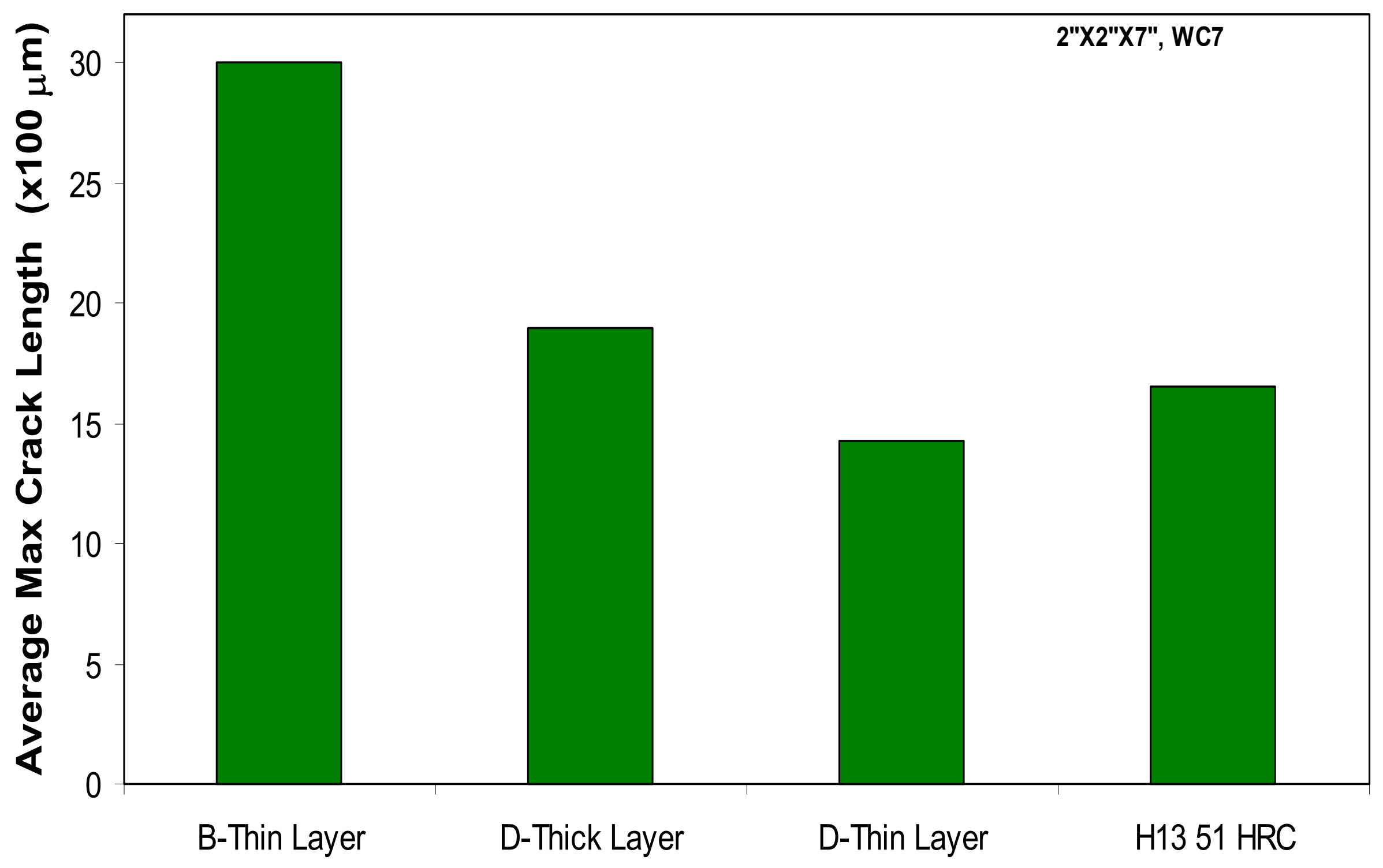

